\title{
Forecasting the volatility of Bitcoin: the importance of jumps and structural breaks
}

Article

Accepted Version

Shen, D., Urquhart, A. ORCID: https://orcid.org/0000-00018834-4243 and Wang, P. (2020) Forecasting the volatility of Bitcoin: the importance of jumps and structural breaks.

European Financial Management, 26 (5). pp. 1294-1323. ISSN 1468-036X doi: https://doi.org/10.1111/eufm.12254 Available at https://centaur.reading.ac.uk/87932/

It is advisable to refer to the publisher's version if you intend to cite from the work. See Guidance on citing.

To link to this article DOI: http://dx.doi.org/10.1111/eufm.12254

Publisher: Wiley

All outputs in CentAUR are protected by Intellectual Property Rights law, including copyright law. Copyright and IPR is retained by the creators or other copyright holders. Terms and conditions for use of this material are defined in the End User Agreement.

\section{www.reading.ac.uk/centaur}

\section{CentAUR}

Central Archive at the University of Reading 
Reading's research outputs online 


\title{
Forecasting the Volatility of Bitcoin: The Importance of Jumps and Structural Breaks ${ }^{1}$
}

\author{
Dehua Shen \\ College of Management and Economics \\ Tianjin University \\ Tianjin \\ China \\ dhs@tju.edu.cn
}

\author{
Andrew Urquhart \\ ICMA Centre \\ Henley Business School \\ University of Reading \\ Reading \\ UK \\ a.j.urquhart@icmacentre.ac.uk
}

\author{
Pengfei Wang * \\ College of Management and Economics \\ Tianjin University \\ Tianjin \\ China \\ pengfeiwang@,tju.edu.cn
}

December 2019

\footnotetext{
${ }^{1}$ This work was supported by the National Natural Science Foundation of China (71701150, 71790594 and 71790590) and Young Elite Scientists Sponsorship Program by Tianjin (TJSQNTJ-2017-09).

* Corresponding author, Tel: +86 13821173051.
} 


\title{
Forecasting the Volatility of Bitcoin: The Importance of Jumps and Structural Breaks
}

\begin{abstract}
This paper studies the volatility of Bitcoin and determines the importance of jumps and structural breaks in forecasting volatility. Using high-frequency data, we perform a modelfree decomposition of realized variance into its continuous and discontinuous components, positive and negative semivariances, signed jumps and leverage components. We show the importance of this decomposition in the in-sample regressions using eighteen competing heterogeneous autoregressive (HAR) models. In the out-of-sample setting, we find that the HARQ-F-J model is the superior model, indicating the importance of the temporal variation and squared jump components at different time horizons. We also show that the HAR models with structural breaks outperform models without structural breaks across all forecasting horizons. Our results are robust to an alternative jump estimator and estimation method.
\end{abstract}

Keywords: Volatility Forecasting; Bitcoin; Realized Volatility; Jumps; Structural Breaks.

JEL classification: C53; G15; G17. 


\section{Introduction}

Bitcoin has received a great deal of attention since it was first proposed by Nakamoto (2008) and this attention has come from the media, governments, regulators, as well as from investors, who have been attracted to Bitcoin by its huge increase in price during 2017. However with this surge in price in 2017, has come huge volatility and uncertainty regarding the future price path of this popular cryptocurrency. There is a growing evidence that Bitcoin offers substantial diversification to investors when included in portfolios (Kajtazi and Moro 2019; Platanakis and Urquhart 2019) and that technical trading rules generate signficiant returns to investors (Hudson and Urquhart 2019). Therefore, forecasting the volatility of Bitcoin is of great interest and this paper provides a comprehensive overview of the forecasting ability of various time-series models derived from the innovative heterogenous autoregression (HAR) specification of Corsi (2009). We consider eighteen HAR models and the analysis is conducted in-sample, and more importantly, out-of-sample for Bitcoin from January 2012 to September 2018. Our results show that the inclusion of jumps is important when forecasting Bitcoin volatility at all forecasting horizons. Specifically, we find that the HARQ-F-J model provides the best out-of-sample forecast of volatility for a 1-day horizon period indicating the importance of the temporal variation and squared jump components at different horizons. For the 1-week and 1-month forecast horizons, we find a number of models that include jumps are superior to models without jumps. Also, we find that the inclusion of structural breaks in each HAR model improves the forecasting ability of these models when considering forecast horizons of 1-day, 1-week and 1-month. Therefore our results indicate the importance of the temporal variation and squared jump components, separated at different horizons, as well as structural breaks, in forecasting Bitcoin volatility through competing HAR models.

Since the availability of high-frequency data has become more common, there is ample evidence of the economic value of forecasting volatility using intraday data. Most of the studies find that simple autoregressive structures such as HAR models provide much better forecasting ability than GARCHtype models that employ daily data (for instance, see Andersen and Bollerslev (1997); (1998); 
Andersen et al (2001); Andersen et al (2003); Koopman et al (2005); Giot and Laurent (2007)). ${ }^{1}$ This improvement comes from the fact that GARCH models employ daily data while HAR models are able to capture more information contained in intraday data.

The literature on cryptocurrencies is growing, with many papers reporting the inefficiency of Bitcoin (Urquhart 2016; Khuntia and Pattanayak 2018; Nadarajah and Chu 2018; Tiwari et al 2018), the hedging and diversification benefits (Bouri et al 2017; Corbet et al 2018a; Urquhart and Zhang 2018; Borri 2019), the existence of bubbles (Cheah and Fry 2015; Corbet et al 2018b) and the behaviour of Bitcoin returns (Urquhart 2017; Corbet and Katsiampa 2018; Phillip et al 2018). ${ }^{2}$ However there is limited literature examining the volatility dynamics of Bitcoin, with Katsiampa (2017) the first to explore the optimal conditional heteroskedasticity model with regards to goodness-of-fit to Bitcoin and finds that an AR-CGARCH model is the most appropriate, indicating both the short- and long-run component of the conditional variance. Chaim and Luarini (2018) show that jumps to volatility are permanent in Bitcoin, while jumps to returns are contemporaneous. They also show that large jumps to mean returns are all negative and associated with hacks and forks. Catania et al (2019) compare the abilities of several alternative univariate and multivariate models to predictor cryptocurrencies and show large statistically significant improvements in the point forecasting of Bitcoin when using combinations of univariate models while Katsiampa et al (2019) show strong interdependencies between cryptocurrency volatilities and that time-varying conditional correlations of volatility exist between cryptocurrencies. Gronwald (2019) shows that Bitcoin price dynamics are particularly influenced by extreme price movements, more than in the markets for crude oil or gold which is possibly a result of the immaturity of the market. Recently, Kalyvas et al (2019) shows that bitcoin crash risk is lower when economic policy uncertainty is high, indicating the hedging ability of bitcoin to economic policy uncertainty.

\footnotetext{
${ }^{1}$ Andersen et al (2006), chapter 15 provides an excellent survey.

${ }^{2}$ See Corbet et al (2019) for a recent review of the empirical literature of cryptocurrencies.
} 
All of the previously mentioned studies employ daily data but there is growing evidence that highfrequency data is useful in predicting future volatility, especially the decomposition between the continuous and the jump component, as well as the separation between negative and positive intraday returns. Jumps have a long history in finance and have traditionally been estimated from daily data (for instance Andersen et al 2002; Eraker et al 2003; Eraker 2004). However given the upsurge in the availability of high frequency data, more and more studies have gained insights from the intraday behaviour of volatility. Andersen and Bollerslev (1998) were the first to use intraday data to measure volatility when they proposed realized volatility (RV) and since then, high-frequency data applications have developed rapidly with a strong focus on forecasting financial markets. In more recent work, Corsi (2009) proposes the heterogeneous autoregressive model of realized volatility (HAR-RV) and shows that this model is markedly better than the traditional GARCH model and ARFIMA-RV model at forecasting volatility. Since then, many studies have examined the use of the HAR-RV model as well as modifications to the model, such as the HAR-RV-J, HAR-RV-CJ and HAR-RSV model for example. Many studies have shown that these HAR type models offer better forecasting ability than GARCH, SV, VAR-RV and ARFIMA-RV models (see for example Andersen et al 2011; Çelik and Ergin 2014; Sévi 2014) indicating the importance of intraday volatility in forecasting future volatility.

This study provides a comprehensive empirical analysis of the forecasting accuracy of various time series models derived from the heterogenous autoregressive (HAR) specification proposed by Corsi (2009). We study 18 competing HAR models that forecast volatility from 1-day to 2-months where we conduct in-sample and more importantly, out-of-sample analysis of Bitcoin from $1^{\text {st }}$ January 2012 to $30^{\text {th }}$ September 2018. Specifically, we find that the HARQ-F-J model provides the best out-ofsample forecast of volatility for a 1-day, 1-week and 1-month horizons period indicating the importance of the separating temporal variation and squared jump components at different horizons. Also, we find that the inclusion of structural breaks in each HAR model improves the forecasting ability of these models when considering forecast horizons of 1-day, 1-week and 1-month. Therefore our results indicate the importance of the temporal variation and squared jump components, separated 
at different horizons, as well as structural breaks, in forecasting Bitcoin volatility through competing HAR models. We conduct a number of robustness checks where we employ the novel jump-robust estimator of Andersen et al (2012), as well as using a weighted least squares (WLS) approach rather than the OLS and our findings remain consistent. Therefore we find that jumps are quite common in Bitcoin and that jumps as well as structural breaks are important components when forecasting the volatility of Bitcoin.

Our findings are consistent with the results from Scaillet et al (2018) in that jumps are frequent events in the Bitcoin market, and therefore in our paper the inclusion of jumps improves the forecasting power of our HAR models. As argued in Scaillet et al (2018), the presence of "whales", who are big money bitcoin players that show their hand in the bitcoin market, can have a large impact on the price if they make such a big order in the market. These large impacts subsequently cause the jumps in the bitcoin price and the likelihood of "whales" in the bitcoin market is much higher than in equity markets. Therefore bitcoin (and other cryptocurrencies) are more susceptible to jumps than more mature markets. Also, the bitcoin market trades 24 hours a day, 7 days a week which enables traders from all over the world to trade at whatever time is suitable for them. Consequently, unlike international stock markets with certain trading times, not all bitcoin traders are active in the market at the same time and this can lead to certain traders being able to have a large price impact when liquidity in the market is fairly low. We also find that the inclusion of structural breaks in our HAR models produces better forecasts of bitcoin volatility. Similar to jumps, structural breaks are inherent in the bitcoin market due to "whales" and the market structure of bitcoin. This can be clearly seen in Figure 2 where we report the time-series graph of the price of bitcoin during our sample period. In a more mature, less volatile market, the inclusion of structural breaks in HAR models may not be as useful but in the immature bitcoin market, we find that they are very useful. With bitcoin futures introduced in December 2017, investors are now able to hedge bitcoin much more easily which may prevent the huge bubbles experienced in 2015 and 2016 (Shiller 2017) and reduce the number of jumps and structural breaks in the bitcoin price. 
The remainder of the paper is organized as follows. Section 2 introduces are data employed while Section 3 provides the methodology, where we explain how we measure realized volatility, jumps as well the 18 different HAR models employed in this study. Section 4 presents the empirical results and Section 5 provides some robustness checks. Finally, Section 6 provides a summary of the findings and concludes.

\section{Data}

We obtain Bitcoin tick data from www.bitcoincharts.com and focus on Bitstamp from $1^{\text {st }}$ January 2012 to $30^{\text {th }}$ September 2018 since it is one of the largest and longest Bitcoin exchanges and thus provides sufficient liquidity. ${ }^{3}$ The sample period is chosen due to data availability as before this date, Bitcoin lacked intraday liquidity. Bitcoin trades 24 hours a day, 7 days a week and therefore we have a continuous time-series throughout our sample period. ${ }^{4}$ Before computing the variances, a sampling frequency needs to be chosen. It is well documented in the literature that microstructure noise (due to bid-ask spreads, non-synchronous trading and price discreteness) may impact on the realized variance estimator at high frequency (see for example Andersen and Bollerslev 1997; Andersen and Bollerslev 1998). To deal with this issue, we plot the volatility signature in Figure 1, which stabilises around the 5-minute frequency and therefore we use this as our sampling frequency. ${ }^{5}$

Table 1 presents summary statistics for the different measures of variance where we annualize by multiplying by the square root of 365 . We can see that RV is quite large for Bitcoin while we find strong evidence of jumps in this cryptocurrency. Figure 2 and 3 present the time-series graph of the daily price and returns of Bitcoin over our sample period and shows the dramatic price rise and large volatility associated with Bitcoin.

\footnotetext{
${ }^{3}$ Although the volatility of Bitcoin futures may be of interest to forecast, Bitcoin futures only started trading on the CBOE on $10^{\text {th }}$ December 2017 and therefore there is a limited sample size. Future work will no doubt examine the volatility forecasting of Bitcoin futures when the market is more mature, and more data is available. ${ }^{4}$ Since Bitcoin trades $24 / 7$ unlike traditional equity markets which trade only 5 days a week, our 1-week horizons are 7 full days, rather than 5 .

${ }^{5}$ Liu et al (2015) show that it is difficult to beat the standard 5-minute realized variance when forecasting volatility and the use of the 5-minute frequency is consistent with other studies such as Sévi (2014); Wen (2016), Behrendt and Schmidt (2018).
} 


\section{Methodology}

This section provides an overview of estimating volatility from intraday data, the jump detection tests, and then we introduce our competing models.

\subsection{Estimating Volatility}

In order to calculate the realized volatility (RV) from the 5-minutely data, we define any given day $t$, and the RV is computed as the sum of the squared intraday returns $r_{t, j}$ at a given sampling frequency $1 / M:$

$$
R V_{t, M}=\sum_{j=1}^{M} r_{t, j}^{2}
$$

where $M$ is the number of intervals in the trading day. Now we have RV, we now need to disentangle jumps and from the continuous component of RV. Barndorff-Nielsen and Shephard (2004) propose the bi-power variation (BPV) measure, which is computed as the scaled summation of the product of adjacent absolute returns:

$$
B P V_{t, M}=\delta_{1} \sum_{j=1}^{M-1}\left|r_{t, j}\right|\left|r_{t, j+1}\right|
$$

where $\delta_{1} \equiv 2^{\frac{p}{2}} \Gamma\left(\frac{\frac{1}{2(p+1)}}{\Gamma(1 / 2)}\right)=E\left(|Z|_{p}\right)$ denotes the mean of the absolute value of standard normally distributed random variable $Z$.

\subsection{Jump Detection}


We employ the adjusted jump ratio statistic, which has been shown to have power against several empirically realistic calibrated stochastic volatility jumps diffusion models and the best empirical properties in Huang and Tauchen (2005), to detect jumps in our study. The test statistic is as follows:

$$
Z J_{B P V}(t, M)=\sqrt{M} \frac{\left(R V_{t, M}-B P V_{t, M}\right) R V_{t, M}^{-1}}{\left(\left(\zeta_{1}^{-4}+2 \zeta_{1}^{-2}-5\right) \max \left\{1, T Q_{t, M} B P V_{t, M}^{-2}\right\}\right)^{1 / 2}}
$$

where $T Q_{t, M}$ is the realized tripower quarticity which writes $T Q_{t, M}=M \zeta_{4 / 3}^{3} \sum_{j=1}^{M-2}\left|r_{t, j+1}\right|^{4 / 3}\left|r_{t, j+2}\right|^{4 / 3}$ and converges in probability to the integrated quarticity. The $Z J_{B P V}$ statistic follows a standard normal distribution and allows formal testing for the presence of jumps.

Using the test statistic in equation (3) and a significance level of $\alpha$ which we set to 0.999 , we extract significant jumps as follows ${ }^{6}$ :

$$
J_{t, \alpha}(M)=\left[R V_{t, M}-B P V_{t, M}\right] \times I\left[Z J_{B P V}(t, M)>\Phi_{\alpha}\right]
$$

where $I[$.$] is the indicator function which identifies the significance of the Z J_{B P V}(t, M)$ statistic in excess of a given critical value of the Gaussian distribution $\Phi_{\alpha}$. The continuous path of realized variance can be identified as:

$$
C_{t, \alpha}(M)=B P V_{t, M} \times I\left[Z J_{B P V}(t, M)>\Phi_{\alpha}\right]+R V_{t, M} \times I\left[Z J_{B P V}(t, M) \leq \Phi_{\alpha}\right]
$$

Therefore if a jump is present, the squared jump component equals the difference between RV and $\mathrm{BPV}$ and the continuous component equals the BPV. If there are no jumps, the jump component is naturally zero and the continuous component equals RV.

\subsection{Semivariances and signed jumps}

\footnotetext{
${ }^{6}$ We follow Bajgrowicz et al (2014) and Prokopczuk et al (2016) and choose this criterion to allay concerns that the test may be driven by false positives.
} 
Realized semivariances have been shown to have importance in volatility forecasting (BarndorffNielson et al 2010) since negative and positive returns will have different impacts on the volatility. Therefore the daily negative realized semivariances estimator is:

$$
R S V_{t, M}^{-}=\sum_{j=1}^{M} r_{t, j}^{2} \times I_{\left|r_{t, j}<0\right|}
$$

And the positive realized semivariances estimator is:

$$
R S V_{t, M}^{+}=\sum_{j=1}^{M} r_{t, j}^{2} \times I_{\left|r_{t, j}>0\right|}
$$

From both these, we follow Patton and Sheppard (2011) and define signed jumps as the difference between positive and negative realized semivariances:

$$
\Delta J_{t, M}=R S V_{t, M}^{+}-R S V_{t, M}^{-}
$$

\subsection{HAR Models}

In this section, we introduce the eighteen different HAR models we examine in this paper.

\subsubsection{HAR-RV Model}

Based on the heterogenous market hypothesis of Corsi (2009) proposes the HAR-RV model:

$$
\overline{R V}_{t+H}^{d}=\beta_{0}+\beta_{1} R V_{t}^{d}+\beta_{7} R V_{t}^{w}+\beta_{30} R V_{t}^{m}+\varepsilon_{t+H}
$$


where $\overline{R V}_{t+H}^{d}$ is the average realized volatility between time $t$ and $t+H . \overline{R V}_{t+1}^{d}$ represents the 1-day future realized volatility, while $\overline{R V}_{t+7}^{d}$ represents the 1-week future realized volatility and $\overline{R V}_{t+30}^{d}$ represents the 1-monith future realized volatility. $R V_{t}^{d}=R V_{t}^{d 0}+r_{t, n}^{2}$ is the daily realized volatility, $R V_{t}^{w}=\left(R V_{t}^{d}+R V_{t-1}^{d}+\ldots+R V_{t-6}^{d}\right) / 7$ is the weekly realized volatility while $R V_{t}^{m}=\left(R V_{t}^{d}+\right.$ $\left.R V_{t-1}^{d}+\ldots+R V_{t-29}^{d}\right) / 30$ is the monthly realized volatility.

\subsubsection{HAR-RV-J Model}

To determine whether the inclusion of a jump component can help forecast volatility, Andersen et al (2007) develop this model by adding the daily discontinuous jump variation to the HAR-RV model such that:

$$
\overline{R V}_{t+H}^{d}=\beta_{0}+\beta_{1} R V_{t}^{d}+\beta_{7} R V_{t}^{w}+\beta_{30} R V_{t}^{m}+\beta_{S Q J 1} J_{t}^{d}+\varepsilon_{t+H}
$$

where $J_{t}^{d}$ is the daily discontinuous jump variation that we defined in equation (4).

\subsubsection{HAR-CJ Model}

The HAR-CJ model, proposed by Andersen et al (2007), separates out the continuous and squared jumps components at different time horizons. This model can assess the role of these different volatility components in forecasting volatility such that:

$$
\overline{R V}_{t+H}^{d}=\beta_{0}+\beta_{C 1} C_{t}^{d}+\beta_{C 7} C_{t}^{w}+\beta_{C 30} C_{t}^{m}+\beta_{S Q J 1} J_{t}^{d}+\beta_{S Q J 7} J_{t}^{w}+\beta_{S Q J 7} J_{t}^{m}+\varepsilon_{t+H}
$$

where $C_{t}^{d}$ is the daily continuous sample path variation as measure, $C_{t}^{w}=\left(C_{t}^{d}+C_{t-1}^{d}+\ldots+C_{t-4}^{d}\right) / 7$ is the weekly continuous sample path variation, and $C_{t}^{m}=\left(C_{t}^{d}+C_{t-1}^{d}+\ldots+C_{t-29}^{d}\right) / 30$ is the monthly continuous path variation. The jump component is also decomposed in the following way: 
$J_{t}^{w}=\left(J_{t}^{d}+J_{t-1}^{d}+\ldots+J_{t-4}^{d}\right) / 7$ is the weekly jump variation, and $J_{t}^{m}=\left(J_{t}^{d}+J_{t-1}^{d}+\ldots+J_{t-29}^{d}\right) / 30$ is the monthly jump variation.

\subsubsection{HAR-PS Model}

This model is the basic specification of Patton and Sheppard (2011) which decomposes the one-day lagged realized variance into a positive and negative component using realized semivariances such that:

$$
\overline{R V}_{t+H}^{d}=\beta_{0}+\beta_{1}^{+} R S V_{t}^{+}+\beta_{1}^{-} R S V_{t}^{-}+\beta_{7} R V_{t}^{w}+\beta_{30} R V_{t}^{m}+\varepsilon_{t+H}
$$

\subsubsection{HAR-PSL Model}

This model is similar to the previous HAR-PS model but includes a term for the leverage effect, and checks whether the superior significance of negative realized semivariance does not come from a leverage effect:

$$
\overline{R V}_{t+H}^{d}=\beta_{0}+\beta_{1}^{+} R S V_{t}^{+}+\beta_{1}^{-} R S V_{t}^{-}+\gamma R V_{t} I_{\left[r_{t}<0\right]}+\beta_{7} R V_{t}^{w}+\beta_{30} R V_{t}^{m}+\varepsilon_{t+H}
$$

\subsubsection{HAR-RSV Model}

This model by Patton and Sheppard (2011) decomposes realized variance into a positive and negative component using realized semivariances, since the model assumes that positive and negative realized semivariances can have different predictive abilities for the short, medium and long terms. The HARRSV model is such that:

$$
\begin{gathered}
\overline{R V}_{t+H}^{d}=\beta_{0}+\beta_{1}^{+} R S V_{t}^{d+}+\beta_{7}^{+} R S V_{t}^{w+}+\beta_{30}^{+} R S V_{t}^{m+}+\beta_{1}^{-} R S V_{t}^{d-}+\beta_{7}^{-} R S V_{t}^{w-} \\
+\beta_{30}^{-} R S V_{t}^{m-}+\varepsilon_{t+H}
\end{gathered}
$$


where $R S V_{t}^{d+}$ represents the daily positive realized semivariance, $R S V_{t}^{w+}$ represents the weekly positive realized semivariance and $R S V_{t}^{m+}$ represents the monthly positive realized semivariance, while $R S V_{t}^{d-}$ represents the daily negative realized semivariance, $R S V_{t}^{w-}$ represents the weekly negative realized semivariance and $R S V_{t}^{m-}$ represents the monthly negative realized semivariance.

\subsubsection{HAR-RSV-J Model}

Chen and Ghysels (2011) propose the HAR-RSV-J model, which is similar to the HAR-RSV model but includes the lagged daily discontinuous jump variation such that:

$$
\begin{gathered}
\overline{R V}_{t+H}^{d}=\beta_{0}+\beta_{1}^{+} R S V_{t}^{d+}+\beta_{7}^{+} R S V_{t}^{w+}+\beta_{30}^{+} R S V_{t}^{m+}+\beta_{1}^{-} R S V_{t}^{d-}+\beta_{7}^{-} R S V_{t}^{w-} \\
+\beta_{30}^{-} R S V_{t}^{m-}+\beta_{S Q J 1} J_{t}^{d}+\varepsilon_{t+H}
\end{gathered}
$$

\subsubsection{HARQ-F Model}

Recently, Bollerslev et al. (2016) propose the HARQ-type model by incorporating Realized Quarticity (RQ) into the basic models, where $R Q=\frac{M}{3} \sum_{j=1}^{M} r_{t, j}^{2}$.

$$
\begin{aligned}
\overline{R V}_{t+H}^{d}=\beta_{0}+ & \left(\beta_{1}+\beta_{R Q 1} \sqrt{R Q_{t}^{d}}\right) R V_{t}^{d}+\left(\beta_{7}+\beta_{R Q 7} \sqrt{R Q_{t}^{m}}\right) R V_{t}^{w} \\
& +\left(\beta_{30}+\beta_{R Q 30} \sqrt{R Q_{t}^{m}}\right) R V_{t}^{m}+\varepsilon_{t+H}
\end{aligned}
$$

where $R Q_{t}^{w}=\left(R Q_{t}^{d}+R Q_{t-1}^{d}+\ldots+R Q_{t-6}^{d}\right) / 7$ is the weekly realized quarticity while $R Q_{t}^{m}=$ $\left(R Q_{t}^{d}+R Q_{t-1}^{d}+\ldots+R q_{t-29}^{d}\right) / 30$ is the monthly realized quarticity. Since equation (16) contains all parameters of measurement of error variance compared to the simplified model described in subsection 3.4.10, this model is termed the HARQ-F model.

\subsubsection{HARQ-F-J Model}

The HARQ-F-J model is a new specification where the jump component with a positive sign is considered based on the HARQ-F model proposed by Bollerslev et al. (2016), which has significantly improved the forecasting accuracy by incorporating temporal variation. We further add the jump component to the HARQ model: 


$$
\begin{aligned}
\overline{R V}_{t+H}^{d}=\beta_{0}+ & \left(\beta_{1}+\beta_{R Q 1} \sqrt{R Q_{t}^{d}}\right) R V_{t}^{d}+\left(\beta_{7}+\beta_{R Q 7} \sqrt{R Q_{t}^{m}}\right) R V_{t}^{w} \\
& +\left(\beta_{30}+\beta_{R Q 30} \sqrt{R Q_{t}^{m}}\right) R V_{t}^{m}+\beta_{S Q J 1} J_{t}^{d}+\varepsilon_{t+H}
\end{aligned}
$$

where $J_{t}^{d}$ is the daily discontinuous jump variation.

\subsubsection{HARQ Model}

Bollerslev et al. (2016) also observe that there exists substantial estimation bias in daily $R V$, while the attenuation bias is much less severe in the weekly and monthly ones. Therefore, they simplify equation (16) to the function of daily $R Q^{\frac{1}{2}}$.

$$
\overline{R V}_{t+H}^{d}=\beta_{0}+\left(\beta_{1}+\beta_{R Q 1} \sqrt{R Q_{t}^{d}}\right) R V_{t}^{d}+\beta_{7} R V_{t}^{w}+\beta_{30} R V_{t}^{m}+\varepsilon_{t+H}
$$

which is referred to the HARQ model.

\subsubsection{HARQ-J Model}

As the HAR-Q-F model has its simplified version, the new specification of HARQ-F-J model can be also termed as HARQ-J by only focusing on daily realized quarticity and jump component, which is the second new specification:

$$
\overline{R V}_{t+H}^{d}=\beta_{0}+\left(\beta_{1}+\beta_{R Q 1} \sqrt{R Q_{t}^{d}}\right) R V_{t}^{d}+\beta_{7} R V_{t}^{w}+\beta_{30} R V_{t}^{m}+\beta_{S Q J 1} J_{t}^{d}+\varepsilon_{t+H}
$$

\subsubsection{HAR-RV-SJ Model}

This model introduces the notion of the signed jump and is similar to the previous HAR-RV-J model but now the lagged daily discontinuous jump variation is replaced with the lagged daily signed jump such as: 


$$
\overline{R V}_{t+H}^{d}=\beta_{0}+\beta_{7} R V_{t}^{w}+\beta_{30} R V_{t}^{m}+\beta_{C 1} C_{t}^{d}+\beta_{J 1} \Delta J_{t}^{d}+\varepsilon_{t+H}
$$

where $\Delta J_{t}^{d}$ is the daily signed jump.

\subsubsection{HAR-CSJ Model}

This model, suggested by Sévi (2014), considers signed jumps over a longer interval than one day and considers jumps over the short period of time, as well as takes account the signs of the jumps such that:

$$
\overline{R V}_{t+H}^{d}=\beta_{0}+\beta_{C 1} C_{t}^{d}+\beta_{C 7} C_{t}^{w}+\beta_{C 30} C_{t}^{m}+\beta_{J 1} \Delta J_{t}^{d}+\beta_{J 7} \Delta J_{t}^{w}+\beta_{J 30} \Delta J_{t}^{m}+\varepsilon_{t+H}
$$

\subsubsection{HAR-RV-SJd Model}

This model, proposed by Patton and Sheppard (2011), discriminates between positive and negative signed jumps such that:

$$
\overline{R V}_{t+H}^{d}=\beta_{0}+\beta_{7} R V_{t}^{d}+\beta_{30} R V_{t}^{w}+\beta_{C 1} C_{t}+\beta_{J 1}^{+} \Delta J_{t}^{d} I_{\left[\Delta J_{t}>0\right]}+\beta_{J 1}^{-} \Delta J_{t}^{d} I_{\left[\Delta J_{t}<0\right]}+\varepsilon_{t+H}
$$

\subsubsection{HAR-CSJd Model}

The HAR-CSJd model is proposed by Sévi (2014) and separates positive and negative signed jumps at various time horizons such that:

$$
\begin{gathered}
\overline{R V}_{t+H}^{d}=\beta_{0}+\beta_{J 1}^{+} \Delta J_{t} I_{\left[\Delta J_{t}>0\right]}+\beta_{J 1}^{-} \Delta J_{t}^{d} I_{\left[\Delta J_{t}<0\right]}+\beta_{C 1} C_{t}^{d}+ \\
\beta_{J 7}^{+} \Delta J_{t}^{w} I_{\left[\Delta J_{t}^{w}>0\right]}+\beta_{J 7}^{-} \Delta J_{t}^{w} I_{\left[\Delta J_{t}^{w}<0\right]}+\beta_{C 7} C_{t}^{w}+ \\
\beta_{J 30}^{+} \Delta J_{t}^{m} I_{\left[\Delta J_{t}^{m}>0\right]}+\beta_{J 30}^{-} \Delta J_{t}^{m} I_{\left[\Delta J_{t}^{m}<0\right]}+\beta_{C 30} C_{t}^{m}+ \\
+\varepsilon_{t+H}
\end{gathered}
$$




\subsubsection{HAR-J}

Proposed by Andersen et al (2007), this model is a simple extension of the HAR-RV model in that it replaces the most recent RV with a continuous and jump component such that:

$$
\overline{R V}_{t+H}^{d}=\beta_{0}+\beta_{C 1} C_{t}^{d}+\beta_{7} R V_{t}^{w}+\beta_{30} R V_{t}^{m}+\beta_{J 1} J_{t}^{d}+\varepsilon_{t+H}
$$

\subsubsection{HAR-RJ}

The previous model can be criticized in that it ignores the sign of the jumps and therefore Tauchen and Zhou (2011) propose the HAR-RJ model such that:

$$
\begin{gathered}
\overline{R V}_{t+H}^{d}=\beta_{0}+\beta_{C 1} C_{t}^{d}+\beta_{7} R V_{t}^{w}+\beta_{30} R V_{t}^{m}+\beta_{R j} R J_{t}+\varepsilon_{t+H} \\
\text { where } R J_{t}=\operatorname{sign}\left(r_{t}\right) \cdot \sqrt{J_{t}}
\end{gathered}
$$

\subsubsection{HAR-ARJ}

The final model, suggested by Prokopczuk et al (2016), decomposes RJ into positive and negative jumps to determine whether the variation from negative jumps has a more pronounced impact on future volatility than that of positive jumps, such that:

$$
R V_{t+h}=\beta_{0}+\beta_{C 1} C_{t}^{d}+\beta_{C 7} C_{t}^{w}+\beta_{C 30} C_{t}^{m}+\beta_{R J^{+}} R J_{t}^{+}+\beta_{R J^{-}} R J_{t}^{-}+\varepsilon_{t+H}
$$

Table 2 provides an overview of the eighteen different HAR models explored in this study which includes the traditionally popular HAR models, as well as more advanced and innovative models. 


\section{Empirical results}

This section presents our main results. We begin by comparing the predictive ability of our models in an in-sample setting, and then present a comprehensive and rigorous analysis of the out-of-sample performance of these models.

\subsection{In-Sample Analysis}

We begin by analysing the in-sample predictive power of our competing models introduced in the previous section. We do this by estimating all the of models noted in the previous section through OLS regressions and also report the adjusted- $\mathrm{R}^{2}$. We consider different forecasting horizons, notably 1-day, 1-week and 1-month volatility, where we use Newey-West corrected standard errors. ${ }^{7}$

Table 3 reports our results for models (1) to (9) for each forecasting horizon and we see that in the HAR-RV model, all coefficients are statistically significant at the $10 \%$ level for all forecasting horizons and the adjusted- $\mathrm{R}^{2}$ for the 1-day, 1-week and 1-month forecasting horizons is $31.8 \%, 34.6 \%$ and $13.2 \%$ respectively. The HAR-RV-J model, which encompasses the jump component, shows that the jump component is positive and statistically significant, which is found across all forecasting horizons, which indicates that volatility increases following a jump event. The jump component magnitude decreases monotonically from the 1-day forecasting horizon to the 1-month forecasting horizon. The adjusted- $\mathrm{R}^{2}$ of the HAR-RV-J model is larger than that of the HAR-RV model, indicating that the HAR-RV-J model incorporating jumps predicts Bitcoin volatility more accurately than the standard HAR-RV model. This is consistent with the results of Corsi et al (2010) who find a positive and significant effect of the jump component when measuring the squared jumps using their threshold indicator. Therefore we can conclude that jumps significantly increase the impact of lagged volatility that is a highly persistent component.

\footnotetext{
${ }^{7}$ We do not put the standard errors in parentheses to conserve space, but the full results are available upon request from the corresponding author.
} 
The results for the HAR-RV-CJ model show that the continuous jump component for one day is positive and statistically significant across all forecasting horizons and has a higher adjusted- $\mathrm{R}^{2}$ to that of the HAR-RV-J model in 1-week and 1-month horizons, indicating its superiority. The HAR-PS model of Patton and Sheppard (2011) shows that the negative semi-variance is statistically significant, however the adjusted- $\mathrm{R}^{2}$ is smaller than that of the HAR-RV-CJ model therefore indicating that the decomposition between positive and negative semivariances does not contribute to improving the fit of the predictive regressions. The HAR-PSL model shows that the leverage component is statistically significant and the high adjusted- $\mathrm{R}^{2}$ shows that this model is the best model for the in-sample 1-day forecasting horizon. For the HAR-RSV model of Patton and Sheppard (2011) and the extension HARRSV-J model of Chen and Ghysels (2011), we find that the jump component is statistically significant as are the RV components decomposed into positive and negative realized semivariances. In the last two rows of Table 3 we report the HARQ-F model of Bollerslev et al (2016) and the HARQ-F-J and find that the new components incorporated by this model are all statistically significant at the 1-day forecasting horizon, and most are statistically significant at the 1-week and 1-month forecasting horizons. Regarding the goodness-of-fit of our models, we find that the model with the highest adjusted- $\mathrm{R}^{2}$ over the one-day horizon is the HAR-PSL while the HARQ-F-J model has the highest adjusted- $\mathrm{R}^{2}$ over the 1-week and 1-month forecasting horizons.

Table 4 presents the findings for models (10) to (18) where we find that the models incorporating realized quarticity, i.e., HARQ and HARQ-J models have larger adjusted-R ${ }^{2}$ compared to the standard HAR models. The signed jump component of the HAR-RV-SJ model is negative and statistically significant at the $5 \%$ level. The explanatory power of this compared to the HAR-RSV-J model is smaller indicating that there is no specific in-sample gain in considering signed jumps. We do show however that there is an additional increase in explanatory power when signed jumps are considered separately depending on their sign. We find that positive and negative 1-day jumps are significant across all forecasting horizons however these models do not offer any higher explanatory power than the HAR-RSV-J model reported in Table 3. We also study the HAR-J model of Andersen et al (2007) and show that this simple model does not add any explanatory power. Finally we examine two further 
models, namely the HAR-RJ model of Tauchen and Zhou (2011) and the HAR-ARJ of Prokopczuk et al (2016). We find that the jump component is negative and statistically significant, indicating that volatility decreases following a jump event. When we decompose the jump component into positive and negative jumps in the HAR-ARJ model, we find that the negative jump component dominates its positive counterpart (consistent with Prokopczuk et al 2016). The adjusted- $\mathrm{R}^{2}$ is also high for the HAR-ARJ model, as it is the model that has the most explanatory power for the 1-day forecasting horizon, and it is quite high compared to the other models for the 1-week and 1-month forecasting horizons.

Combining Tables 3 and 4 together, we find that the model with the highest adjusted- $\mathrm{R}^{2}$ is the HARARJ over the one-day horizon, while the HARQ-F-J model generates the highest adjusted-R ${ }^{2}$ over the one-week and one-month horizons.

\subsection{Out of sample analysis}

We now turn our attention to the out-of-sample performance of the competing models since this is the only way to gauge the forecasting performance between different models (Giot and Laurent 2007). A vast majority of the literature employs the Diebold-Mariano-White (DMW) statistic developed by Diebold and Mariano (1995) and West (1996). This statistic compares the forecast ability of competing models by generating a loss function that is a measure of the difference between the realized value and the forecast in a pseudo out-of-sample forecasting environment. However, the DMW test is inappropriate when comparing nested models, and therefore we use the Clark and West (2007) statistic when comparing the eighteen competing models. ${ }^{8}$ The MSPE-adjusted suggested by Clark and West (2007) is:

$$
\hat{f}_{t+h}=\left(\hat{e}_{1 \mid t+h}\right)^{2}-\left(\hat{e}_{2 \mid t+h}\right)^{2}+\left(\widehat{y}_{1 \mid t+h}-\widehat{y}_{2 \mid t+h}\right)^{2}
$$

\footnotetext{
${ }^{8}$ In unreported results, we also use the DMW statistic to compare non-nested models and use the CW statistic to compare nested models, consistent with Corsi and Renò (2012). Our results are qualitatively similar and are available upon request from the corresponding author.
} 
where $\hat{e}_{1 \mid t+h}$ is the forecast errors of null model for horizon $h, \hat{e}_{2 \mid t+h}$ is the forecast errors of alternative model for horizon $h$, and $\widehat{y}_{1 \mid t+h}$ and $\widehat{y}_{2 \mid t+h}$ are forecast values of null and alternative models. Then the CW statistic for horizon $h$ is calculated by:

$$
\mathrm{CW}=\frac{\sqrt{N \overline{f_{h}}}}{\sqrt{\operatorname{Var}\left(\hat{f}_{t+h}-\overline{f_{h}}\right)}}
$$

where $\overline{f_{h}}$ is the sample average of $\widehat{f}_{t+h}, N$ is the forecast sample number, and $\operatorname{Var}(\cdot)$ is the sample variance. A rejection of the null model denotes the forecast errors from the alternative model are significantly smaller than the null one. Hence, significant and positive CW statistics indicate the alternative model is the preferred one.

For the 1-day forecast horizon reported in Panel A of Table 5 shows that the HAR-RV model significantly outperforms most of other models except for HARQ, HARQ-J, HARQ-F and HARQ-F models. As expected from the in-sample analysis, the HARQ-F and HARQ-F-J models are very good as they outperform most all other models and most of the time, significantly outperforms them. The HARQ and HARQ-J models both do quite well and significantly outperform most other models, but not as good as the HARQ-F and HARQ-F-J models. The worst models are the HAR-RV-CSJD and HAR-PSL which underperform most of all models. Interestingly, the models with signed jumps or signed variances do offer any improved performance. Considering the 1-week horizon in Panel B, we find similar results in that the HARQ-F and HARQ-F-J models are preferred, which also significantly outperform all other models. Therefore over the 1-day and 1-week forecasting horizons we can conclude that the HARQ-F and HARQ-F-J models offer the best performance however the CW statistic of comparison between HARQ-F and HARQ-F-J isn't significant cross the 1-day and 1-week horizons. Table 6 reports the out-of-sample results for the 1-month forecasting horizon where we find that the HARQ-F-J model outperforms all other models indicating that it gives the best out-of-sample performance. Interestingly however, the second best model is the newly developed HARQ-F model 
of Bollerslev et al. (2016), which outperforms all other models (most of the time significantly outperforms) except the HARQ-F-J model.

To summarize, our findings show although modest findings in the in-sample period, the HARQ-F-J model offers the best out-of-sample performance. This points to the well-known in-sample overfitting issue which does not translate well into good out-of-sample forecasts. Therefore in an out-ofsample setting, we find that temporal variation and squared jump components, separated at different horizons, offer the best forecast of the volatility of Bitcoin.

\section{Robustness Check}

In this section, we add robustness to our analysis by considering HAR models with structural breaks as well as an alternative jump estimator by employing the nearest neighbour estimator of Andersen et al (2012). We add a further robustness check by also employing the weighted least squared estimator in addition to the ordinary least squares estimator.

\subsection{Structural Breaks}

In a recent study, Wen et al (2016) introduce HAR models with structural breaks and show that these models can help explain the volatility of crude oil futures. As shown in Figure 2, the price of Bitcoin has fluctuated hugely over our sample period, and therefore there is the possibility that introducing structural breaks into our HAR models may improve the in-sample and more importantly, the out-ofsample performance. Therefore we employ the Inclán and Tiao (1994) ICSS algorithm to determine the number of break points, where Figure 4 plots the Bitcoin returns with break points and \pm 3 standard deviations and Table 7 reports the structural break periods which are identified by the ICSS algorithm. ${ }^{9}$ We find 35 break points during our sample period, which is quite considerable given our sample period which suggests that the inclusion of structural breaks may improve the performance of the HAR models. Therefore we re-estimate each HAR model but include a structural break as in Wen

\footnotetext{
9 The ICSS algorithm is a popular method for detecting multiple structural breaks and has been employed by Vivian and Wohar (2012), Charles et al (2014), Yarovaya et al (2016) and Shahzad et al (2018).
} 
et al (2016) and report the CW statistics of the HAR models with structural breaks over different forecasting horizons in Tables 8 and 9. ${ }^{10}$ Over the 1-day forecasting horizon, we find that the best model is the HARQ-F model which outperforms all other models, while over the 1-week forecasting horizon the relatively superior model is the HAR-J model although it doesn't outperform all models but outperforms the majority of models. Interestingly, over the longer forecasting horizon of 1-month, we find that the HARQ-F model is superior over all others. Therefore the inclusion of the structural breaks into our HAR models changes the superior out-of-sample models quite considerably.

Tables 8 and 9 assess the fit of the HAR models with structural breaks against the HAR models without structural breaks. However we need to assess whether HAR models with structural breaks outperform HAR models without structural breaks included in the estimation to determine whether models with or without structural breaks are superior in the forecasting of volatility of Bitcoin. Therefore in Table 10, we present the CW statistics when comparing HAR models with structural breaks (alternative models) and HAR models excluding structural breaks (null models). In this table, a positive statistic indicates that the corresponding HAR model with structural breaks is preferred over the HAR model without the structural break and we find that over 1-day forecasting horizon, all of the statistics are positive indicating that the HAR models with structural breaks offer the best forecast of future volatility of Bitcoin. When we look at the forecasting horizon of 1-week, we find that the vast majority of the statistics are positive and statistically significant, indicating that HAR models with structural breaks significantly outperform HAR models without structural breaks. Interestingly, when we study the 1-month and 2-months forecasting horizon, we find that the HAR models without structural breaks are sometimes again preferred although the majority of the statistics are positive indicating that the inclusion of structural breaks improves the out-of-sample forecasting power of the HAR models. These results indicate the importance of including structural breaks in forecasting future volatility at forecasting horizons of 1-day and 1-week, but the results are mixed when including structural breaks in HAR models forecasting over 1-month and 2-month horizons.

\footnotetext{
${ }^{10}$ We do not report the in-sample results of the structural break HAR models to conserve space as the out-ofsample analysis is more insightful, but the in-sample results are available upon request from the corresponding author.
} 


\subsection{Alternative Jump Estimators}

As Andersen et al (2012) point out, the standard multipower variations may be biased in finite samples and propose the 'median realized variance estimator' (MedRV) which they show is more efficient and robust to jumps than its main rivals. Therefore we re-estimator our HAR models and replace the BPV with the MedRV variation estimator, where the MedRV can be defined as:

$$
\operatorname{MedRV}_{t}=\frac{\pi}{6-4 \sqrt{3+\pi}}\left(\frac{M}{M-2(k+1)}\right) \sum_{j=2 k+3}^{M} \operatorname{med}\left(\left|r_{t_{j-2(k+1)}}\right|,\left|r_{t_{j-(k+1)}}\right|,\left|r_{t_{j}}\right|\right)^{2}
$$

where med(.) stands for the median operator and more information can be sought from Andersen et al (2012). Similar to the above, we do not report all of the in-sample results to conserve space and focus instead on the out-of-sample analysis. ${ }^{11}$ Table 11 reports the results and our results are consistent with our previous analysis.

\subsection{Alternative Estimation Method}

A potential issue with our previous analysis, as pointed out by Patton and Sheppard (2015), is that the OLS estimation may put too much weight on highly volatile periods since volatility is the dependent variable in the model. To ensure that this is not the driving force behind our results, we re-estimate each model with WLS which employs the inverse of the fitted values as weights for the estimations. We do not report the results to conserve space, but the in-sample and out-of-sample results are very similar to before and we come to the same conclusions. ${ }^{12}$

\section{Summary and Conclusions}

\footnotetext{
${ }^{11}$ Again, the in-sample results are available upon request from the corresponding author.

12 The full results of the WLS regression are available upon request from the corresponding author.
} 
The volatility of Bitcoin has been a source of great interest, debate and worry for investors since Bitcoin is one of the most volatile financial assets. Therefore, forecasting the volatility of Bitcoin is of great interest if investors are considering including Bitcoin in their investment portfolios. This paper presents a comprehensive analysis of the forecasting ability of 18 predictive HAR-type timeseries models in the Bitcoin market. To do this, we collect 5-minute high-frequency data of Bitcoin from Bitstamp and we employ OLS regression with Newey-West standard errors to estimate the model parameters. The in-sample results show that HAR models that include jumps offer more explanatory power than models that exclude jumps, with the HAR-ARJ model superior over the 1-day horizon and the HARQ-F-J model the best model over longer horizons. More importantly, the out-ofsample results also indicate that the inclusion of jumps improves the forecasting ability of HAR models, and that the HARQ-F-J model, which considers the temporal variation and the jump component, is the best model in the out-of-sample setting.

Since the volatility of Bitcoin is so high, and there is the strong possibility of structural breaks, we follow Wen et al (2016) and re-estimate our HAR models but include structural breaks. We find that the inclusions of structural breaks improve the forecasting ability of our HAR models, especially over the 1-day and 1-week forecasting horizons. We also show that our results are robust to alternative jump estimators as well as using WLS as the estimation method rather than the OLS estimation method. Therefore our findings suggest that modelling jumps, especially the temporal variation, and structural breaks significantly improves the accuracy of volatility forecasts of Bitcoin through popular HAR models.

Therefore our results are consistent with the notion that the bitcoin market has large "whales" who are large players that have a big price impact within bitcoin markets (Scaillet et al 2018). This helps explain the large number of jumps and structural breaks in the bitcoin price. Further, the 24 hours a day, 7 days a week trading structure ensures the bitcoin market does not always have the attention of all traders and that there are episodes of illiquidity (as shown in Eross et al 2019). With the 
introduction of bitcoin futures in December 2017, investors are now able to speculate on falling bitcoin prices and may reduce the number of jumps and structural breaks found in the bitcoin market. 


\section{References}

Andersen, T. G., Benzoni, L., Lund, J. (2002). An empirical investigation of continuous-time equity return models. Journal of Finance, 57, 1239-1284.

Andersen, T. G., Bollerslev, T. (1997). Intraday periodicity and volatility persistence in financial markets. Journal of Empirical Finance, 4, 115-158.

Andersen, T. G., Bollerslev, T. (1998). Answering the sceptics: Yes, standard volatility models do provide accurate forecasts. International Economic Review, 39, 885-905.

Andersen, T. G., Bollerslev, T., Christoffersen, P. F., Diebold, F. X. (2006). Volatility and correlation forecasting. In G. Elliot, Granger, C. W. J., Timmermann, A. Handbook of Economic Forecasting.

Andersen, T. G., Bollerslev, T., Diebold, F. X. (2007), Roughing it up: Including jump components in the measurement, modeling and forecasting of return volatility. Review of Economics and Statistics, 89, 701-720.

Andersen, T. G., Bollerslev, T., Diebold, F. X., Ebens, H. (2001). The distribution of stock return volatility. Journal of Financial Econometrics, 61, 43-76.

Andersen, T. G., Bollerslev, T., Diebold, F. X., Labys, P. (2003). Modeling and forecasting realized volatility. Econometrica, 71, 579-625.

Andersen, T. G., Bollerslev, T., Meddahi, N. (2011), Realized volatility forecasting and market microstructure noise. Journal of Econometrics, 160, 220-234.

Andersen, T. G., Dobrev, D., Schaumburg, E. (2012). Jump-robust volatility estimation using nearest neighbour truncation. Journal of Econometrics, 169, 75-93.

Barndorff-Nielson, O. E., Kinnebrock, S., Shephard, N. (2010). Measuring downside risk realized semivariance. In T. Bollerslev, J. Russell and M. Watson. Volatility and time series econometrics: Essays in honor of Robert F. Engle. Oxford University Press.

Barndorff-Nielson, O. E., Shephard, N. (2004). Power and bipower variation with stochastic volatility and jumps. Journal of Financial Econometrics, 2, 1-37.

Behrendt, S., Schmidt, A. (2018). The Twitter Myth Revisited: Intraday Investor Sentiment, Twitter Activity and Individual-Level Stock Return Volatility. Journal of Banking and Finance, 96, 355-367.

Bollerslev, T., Patton, A. J., \& Quaedvlieg, R. (2016). Exploiting the errors: A simple approach for improved volatility forecasting. Journal of Econometrics, 192(1), 1-18.

Bouri, E., Molnár, P., Azzi, G., Roubaud, D., Hagfors, L. I. (2017). On the hedge and safe haven properties of bitcoin: Is it really more than a diversifier? Finance Research Letters, 20, 192-198.

Borri, N. (2019). Conditional tail-risk in cryptocurrency markets. Journal of Empirical Finance, 50, 1-19.

Catania, L., Grassi, S., Ravazzolo, F. (2019). Forecasting cryptocurrencies under model and parameter instability. International Journal of Forecasting, 35, 485-501.

Çelik, S., Ergin, H. (2014), Volatility forecasting using high frequency data: Evidence from stock markets. Economic Modelling, 36, 176-190.

Chaim, P., Laurini, M. P. (2018). Volatility and return jumps in bitcoin. Economics Letters, $173,158-163$.

Charles, A., Darné, O. (2014). Large shocks in the volatility of the Dow Jones Industrial Average index: 1928-2013. Journal of Banking and Finance, 43, 188-199.

Cheah, E. T., Fry, J. (2015). Speculative bubbles in bitcoin markets? An empirical investigation into the fundamental value of bitcoin. Economics Letters, 130, 32-36.

Chen, X., Ghysels, E. (2011). News - good or bad - and its impact on volatility predictions over multiple horizons. Review of Financial Studies, 24, 46-81. 
Clark, T. E., \& West, K. D. 2007. Approximately normal tests for equal predictive accuracy in nested models. Journal of Econometrics, 138(1), 291-311.

Corbet, S., Katsiampa, P. (2018). Asymmetric mean reversion of Bitcoin price returns. International Review of Financial Analysis, forthcoming. Doi: https://doi.org/10.1016/j.irfa.2018.10.004.

Corbet, S., Lucey, B., Yarovaya, L. (2018b), Datestamping the Bitcoin and Ethereum bubbles. Finance Research Letters, 26, 81088.

Corbet, S., Lucey, B., Urquhart, A., Yarovaya, L. (2019). Cryptocurrencies as a financial asset: A systematic analysis. International Review of Financial Analysis, 62, 182-199.

Corbet, S., Meegan, A., Larkin, C., Lucey, B., Yarovaya, L. (2018a). Exploring the dynamic relationships between cryptocurrencies and other financial assets. Economics Letters, $165,28-34$.

Corsi, F. (2009). A simple approximate long-memory model of realized volatility. Journal of Financial Econometrics, 7, 174-196.

Corsi, F., Renò, R. 2012. Discrete-time volatility forecasting with persistent leverage effect and the link with continuous-time volatility modeling. Journal of Business \& Economic Statistics, 30(3), 368-380.

Diebold, F. X., \& Mariano, R. S. (1995). Comparing predictive accuracy. Journal of Business \& Economic Statistics, 13, 253-263.

Eraker, B. (2004). Do stock prices and volatility jump? Reconciling evidence from spot and option prices. Journal of Finance, 59, 1367-1403.

Eraker, B., Johannes, M. S., Polson, N. G. (2003). The impact of jumps in returns and volatility. Journal of Finance, 53, 1269-1300.

Eross, A., McGroarty, F., Urquhart, A., Wolfe, S. (2019). The intraday dynamics of bitcoin. Research in International Business and Finance, 49, 71-81.

Giot, P. and Laurent, S. (2007). The information content of implied volatility in light of the jump/continuous decomposition of realized volatility. Journal of Futures Markets, 27, 337-359.

Gronwald, M. (2019). Is Bitcoin a Commodity? On price jumps, demand shocks, and certainty of supply. Journal of International Money and Finance, 97, 86-92.

Huang, X., Tauchen, G. (2005). The relative price contribution of jumps to total price variance. Journal of Financial Econometrics, 3, 456-499.

Hudson, R., Urquhart, A. (2019). Technical trading and cryptocurrencies. Annals of Operations Research, forthcoming. Doi: https://doi.org/10.1007/s10479-019-03357-1.

Kajtazi, A., Moro, A. (2019). The role of Bitcoin in well diversified portfolios: A comparative global study. International Review of Financial Analysis, 61, 143-157.

Inclàn, C., Taio, G. C. (1994). Use of cumulative sums of squares for retrospective detection of changes of variance. Journal of American Statistical Association, 89, 913-923.

Kalyas, A., Papakyriakou, P., Sakkas, A., Urquhart, A. (2019). What drives Bitcoin's price crash risk? Economics Letters, forthcoming. Doi: https://doi.org/10.1016/j.econlet.2019.108777.

Katsiampa, P. (2017). Volatility estimation for Bitcoin: A comparison of GARCH models. Economics Letters, 158, 3-6.

Katsiampa, P. (2018). Volatility co-movement between Bitcoin and Ether. Finance Research Letters, 30, 221-227.

Katsiampa, P., Corbet, S., Lucey, B. (2019). High frequency volatility co-movements in cryptocurrency markets. Journal of International Financial Markets, Institutions and Money, 62, 35-52.

Khuntia, S., Pattanayak, J. (2018). Adaptive market hypothesis and evolving predictability of bitcoin. Economics Letters, 167, 26-28. 
Koopman, S. J., Jungbacker, B., Hol, E. (2005). Forecasting daily variability of the S\&P100 stock index using historical, realised and implied volatility measurements. Journal of Empirical Finance, 12, 445-475.

Liu, L. Y., Patton, A. J., Sheppard, K. (2015). Does anything beat 5-minute RV? A comparison of realized measures across multiple asset classes. Journal of Econometrics, 187, 293-311.

Nadarajah, S., Chu, J. On the inefficiency of bitcoin. Economics Letters, 150, 6-9.

Nakamoto, S. (2008). Bitcoin: A peer-to-peer electronic cash system. Available at https://bitcoin.org/bitcoin.pdf

Newey, W. K., \& West, K. D. (1987). A simple, positive semidefinite, heteroskedasticity and autocorrelation consistent covariance matrix. Econometrica, 55, 703-708.

Patton, A. J. (2011). Volatility forecast comparison using imperfect volatility proxies. Journal of Econometrics, 160, 246-256.

Patton, A. J., Sheppard, K. (2011). Good volatility, bad volatility: Signed jumps and the persistence of volatility. Unpublished manuscript.

Phillip, A., Chen, J., Peiris, S. (2018). A new look at cryptocurrencies. Economics Letters, $163,6-9$.

Platanakis, E., Urquhart, A. (2019). Should Investors Include Bitcoin in Their Portfolios? A Portfolio Theory Approach. The British Accounting Review, forthcoming. Doi: https://doi.org/10.1016/j.bar.2019.100837.

Prokopczuk, M., Symeonidis, L., Wese Simen, C. (2016). Do Jumps Matter for Volatility Forecasting? Evidence from Energy Markets. Journal of Futures Markets, 36, 758792.

Scaillet, O., Treccani, A., Trevisan, C. (2018). High-Frequency Jump Analysis of the Bitcoin Market. Journal of Financial Econometrics, 1-24.

Sévi, B. (2014). Forecasting the volatility of crude oil futures using intraday data. European Journal of Operational Research, 235, 643-659.

Shahzad, S. J. H., Mensi, W., Hammoudeh, S., Balcilar, M., Shahbaz, M. (2018). Distribution specific dependence and causality between industry-level U.S. credit and stock markets. Journal of International Financial Markets, Institutions and Money, 52, 114133.

Shiller, R. J. (2017). What is bitcoin really worth? Don't even ask. The New York Times, https://www.nytimes.com/2017/12/15/business/bitcoin-investing.html.

Tauchen, G., Zhou, H. (2011)., Realized jumps on financial markets and predicting credit spreads. Journal of Econometrics, 160, 102-118.

Tiwari, A. K., Jana, R. K., Das, D., Roubaud, D. (2018). Informational efficiency of Bitcoin An extension. Economics Letters, 163, 106-109.

Urquhart, A. (2016). The inefficiency of Bitcoin. Economics Letters, 148, 80-92.

Urquhart, A. (2017). Price clustering in Bitcoin. Economics Letters, 159, 145-148.

Urquhart, A., Zhang, H. (2018). Is Bitcoin a hedge of safe-haven for currencies? An intraday analysis. International Review of Financial Analysis, 63, 49-57.

Vivian, A., Wohar, M. E. (2012). Commodity volatility breaks. Journal of International Financial Markets, Institutions and Money, 22, 395-422.

Wen, F., Gong, X., Cai, S. (2016). Forecasting the volatility of crude oil futures using HARtype models with structural breaks. Energy Economics, 59, 400-413.

West, K. D. (1996). Asymptotic inference about predictive ability. Econometrica, 64, 106710.

Yarovaya, L., Brzeszczyński, J., Lau, C. K. M. (2016). Intra- and inter-regional return and volatility spillovers across emerging and developed markets: Evidence from stock 
indices and stock index futures. International Review of Financial Analysis, 43, 96114. 
Figure 1: The volatility signature plot of Bitcoin.

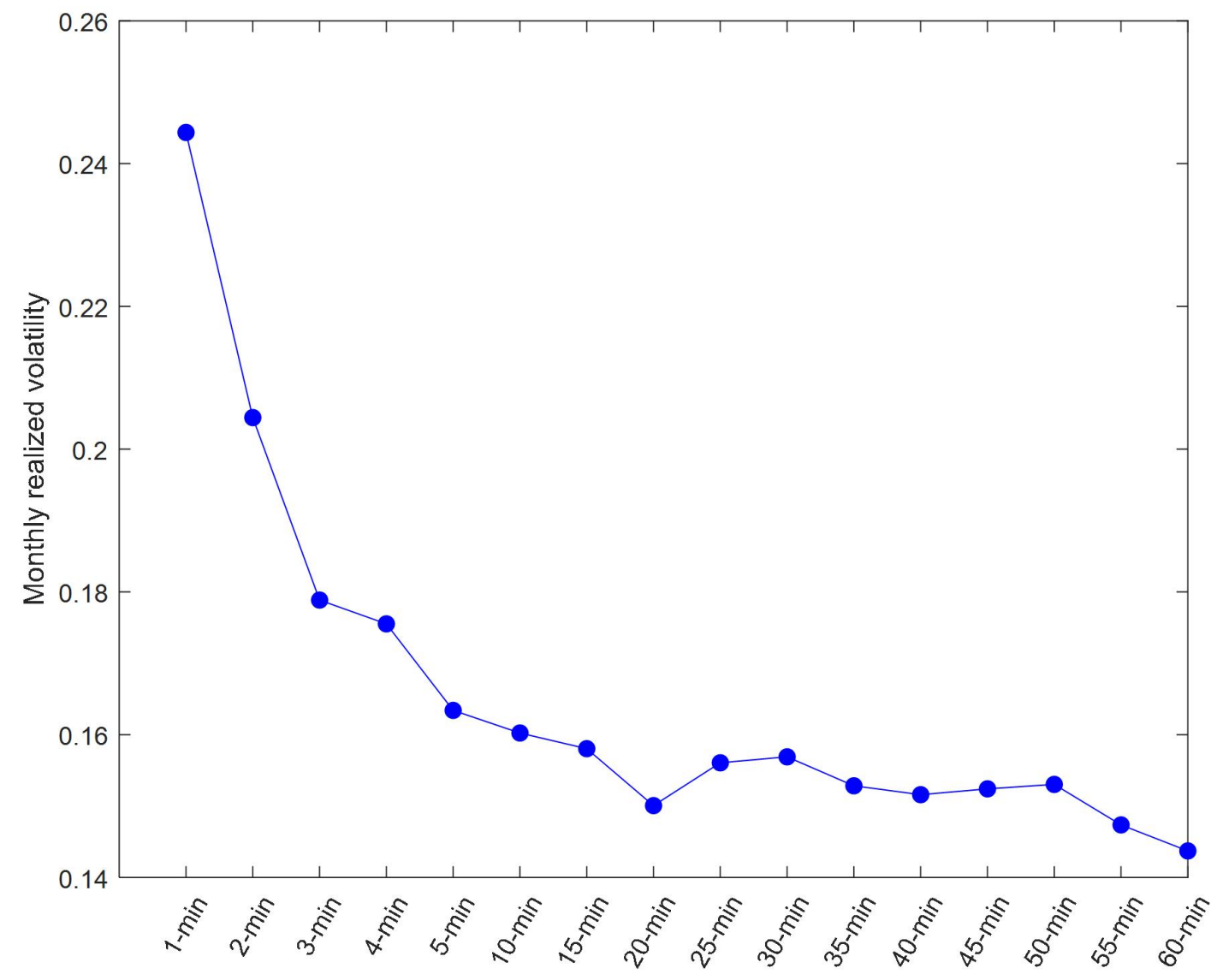


Figure 2: Time-series graph of the price of Bitcoin, in USD, during our sample period.

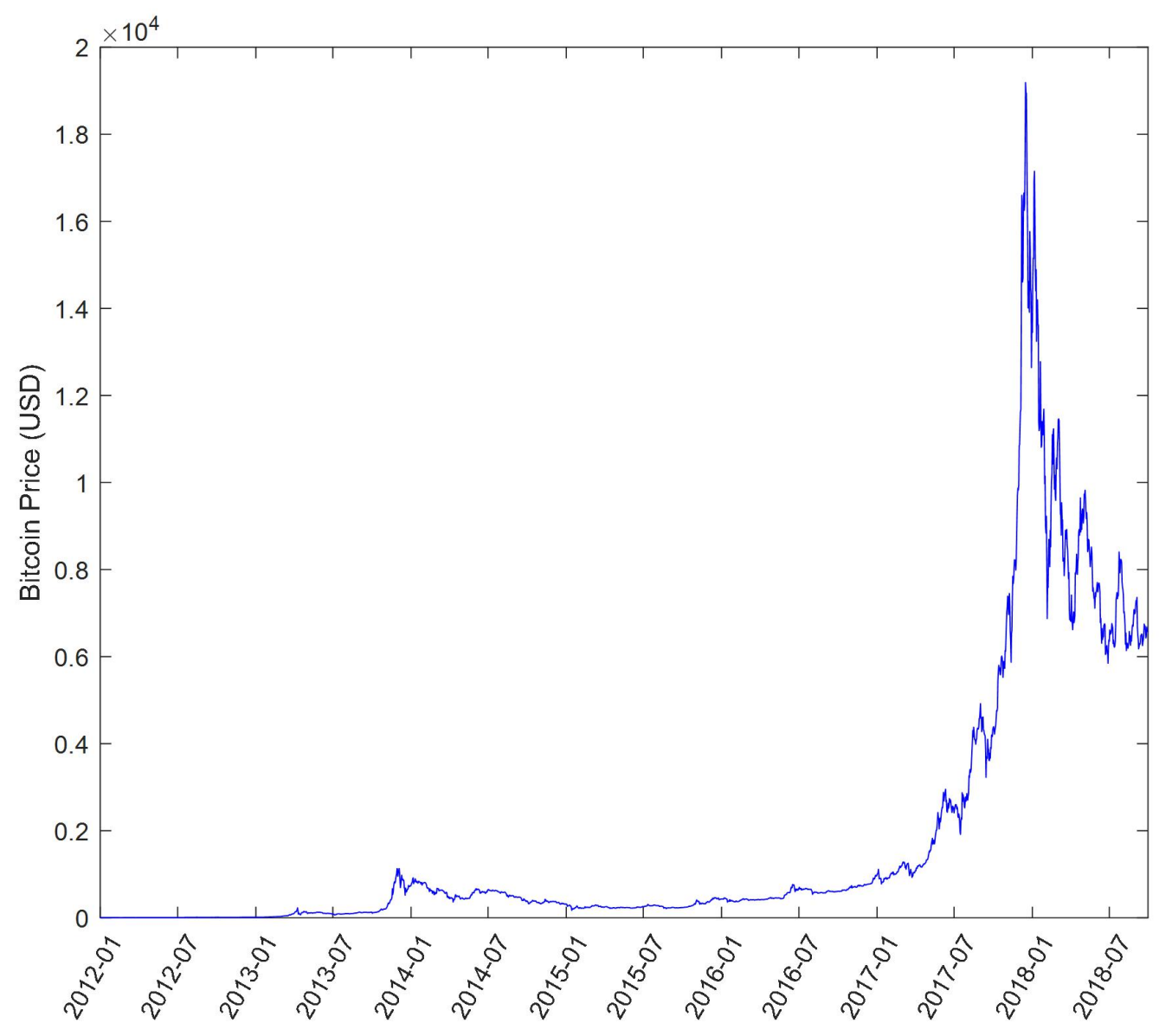


Figure 3: Time-series graph of the returns of Bitcoin, in USD, during our sample period.

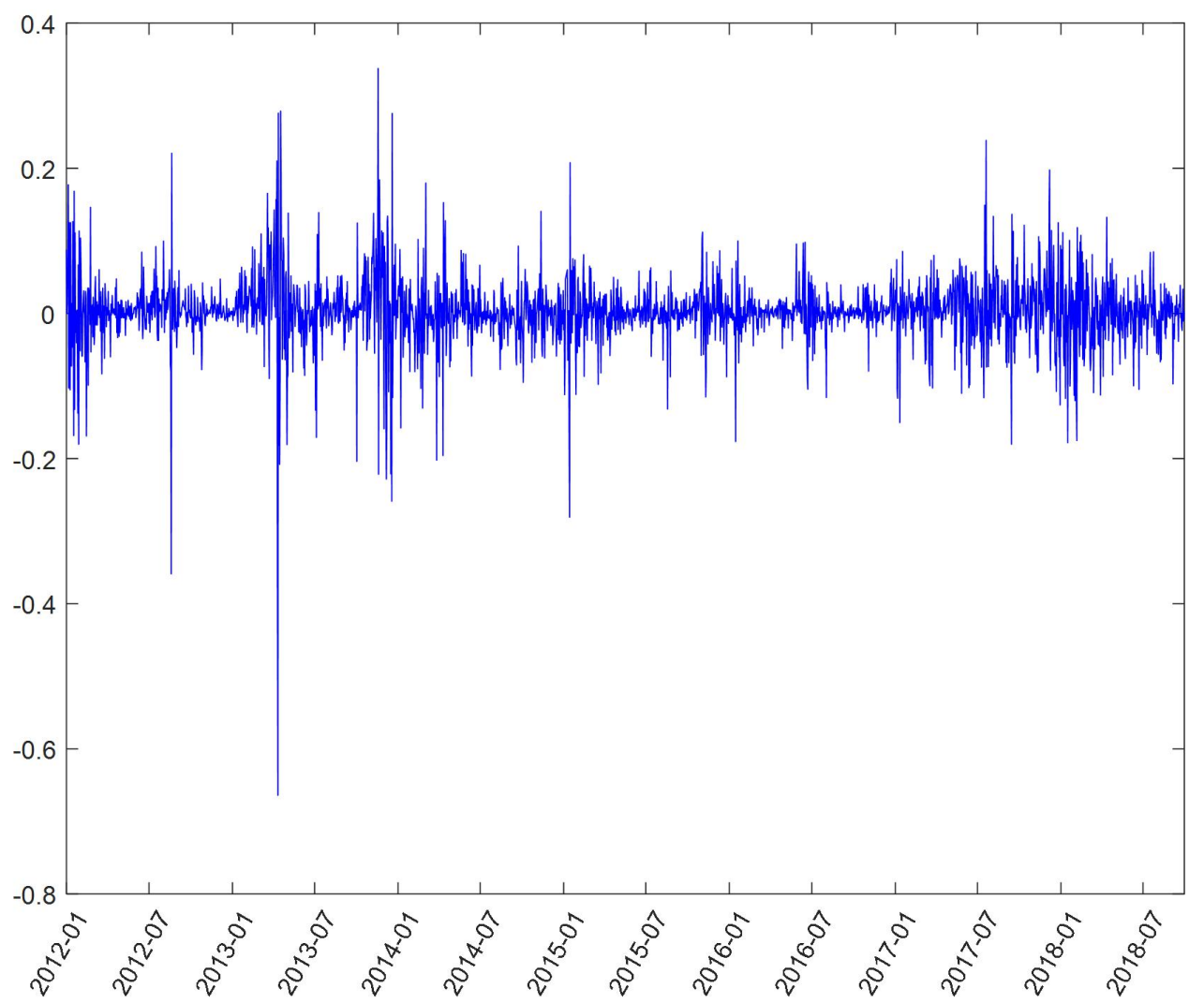


Figure 4: A time-series graph of Bitcoin returns during our sample period, with the structural breaks with \pm 3 standard deviation bounds.

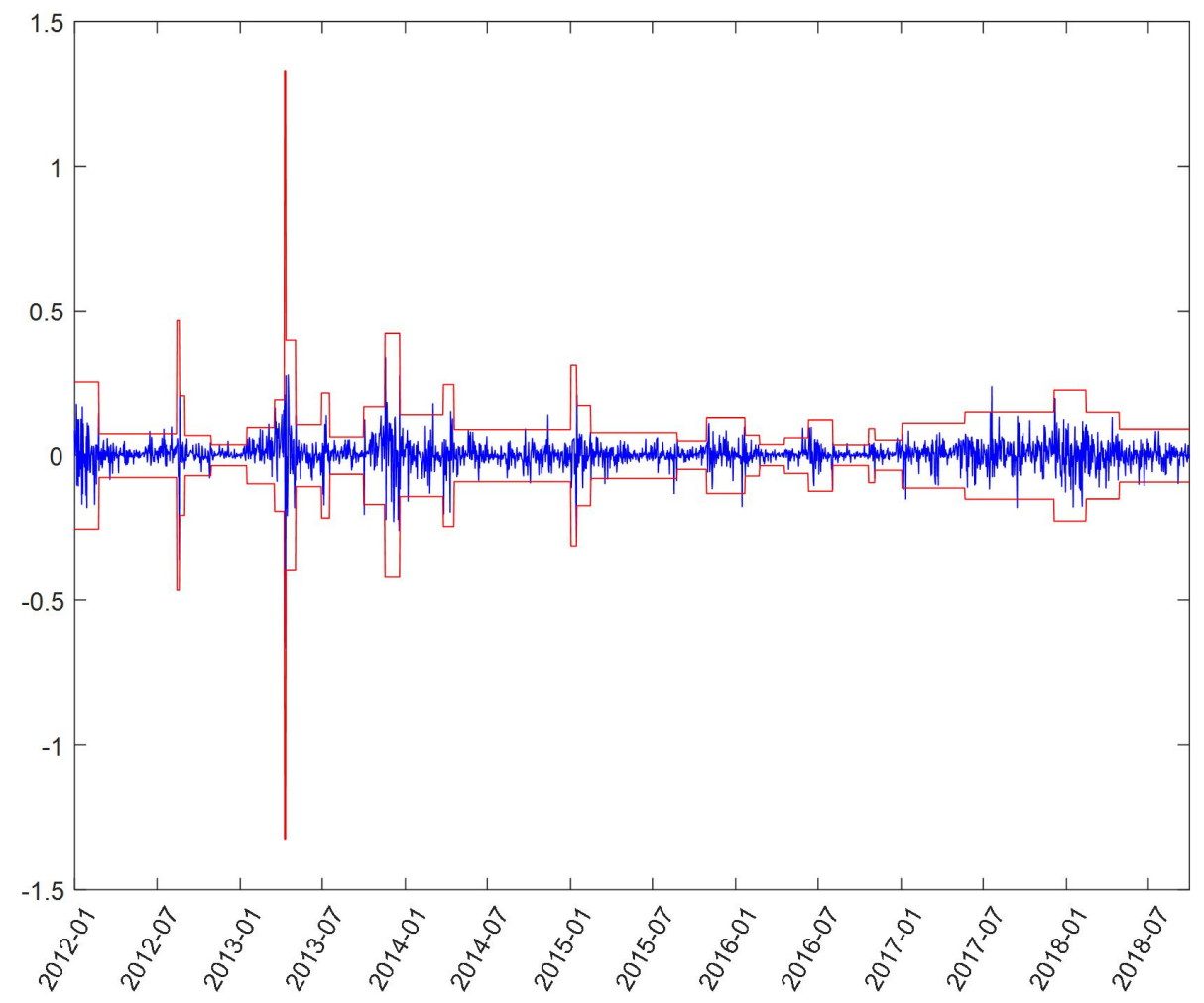


Table 1: Descriptive statistics of the annualized measures of RV.

\begin{tabular}{ccccccc}
\hline & Mean & Std. & Skewness & Kurtosis & Max & Min \\
\hline RV & 0.1051 & 0.5636 & 406.5385 & 10721.5314 & 18.1669 & 0.0000 \\
BPV & 0.0936 & 0.5025 & 391.1610 & 9747.5904 & 15.6355 & 0.0000 \\
J(BPV) & 0.0134 & 0.0802 & 384.3653 & 9900.7244 & 2.5314 & 0.0000 \\
J(MED) & 0.0115 & 0.1586 & 818.6443 & 37854.3913 & 7.4070 & 0.0000 \\
V RV & 1.0164 & 0.9935 & 134.0653 & 1604.9687 & 18.6312 & 0.0745 \\
VBPV & 0.9457 & 0.9381 & 135.5804 & 1615.5471 & 17.2843 & 0.0000 \\
$\sqrt{ }$ (BPV) & 0.3019 & 0.4012 & 118.4355 & 1265.7981 & 6.9542 & 0.0000 \\
$\sqrt{ }$ J(MED) & 0.2006 & 0.4203 & 225.7501 & 5127.5704 & 11.8948 & 0.0000 \\
\hline
\end{tabular}


Table 2: The list of HAR models examined in this paper.

\begin{tabular}{|c|c|c|c|}
\hline Model Number & Model Name & Reference & $\begin{array}{c}\text { Equation number in } \\
\text { this study }\end{array}$ \\
\hline 1 & HAR-RV & Corsi (2009) & Equation (9) \\
\hline 2 & HAR-RV-J & Andersen et al (2007) & Equation (10) \\
\hline 3 & HAR-CJ & Andersen et al (2007) & Equation (11) \\
\hline 4 & HAR-PS & Patton and Sheppard (2011) & Equation (12) \\
\hline 5 & HAR-PSL & Patton and Sheppard (2011) & Equation (13) \\
\hline 6 & HAR-RSV & Patton and Sheppard (2011) & Equation (14) \\
\hline 7 & HAR-RSV-J & Chen and Ghysels (2011) & Equation (15) \\
\hline 8 & HARQ-F & Bollerslev et al. (2016) & Equation (16) \\
\hline 9 & HARQ-F-J & New specification. & Equation (17) \\
\hline 10 & HARQ & Bollerslev et al. (2016) & Equation (18) \\
\hline 11 & HARQ-J & New specification. & Equation (19) \\
\hline 12 & HAR-RV-SJ & Patton and Sheppard (2011) & Equation (20) \\
\hline 13 & HAR-CSJ & Sévi (2014) & Equation (21) \\
\hline 14 & HAR-RV-SJd & Patton and Sheppard (2011) & Equation (22) \\
\hline 15 & HAR-CSJd & Sévi (2014) & Equation (23) \\
\hline 16 & HAR-J & Prokopczuk, et al. (2016) & Equation (24) \\
\hline 17 & HAR-RJ & Prokopczuk, et al. (2016) & Equation (25) \\
\hline 18 & HAR-ARJ & Prokopczuk, et al. (2016) & Equation (26) \\
\hline
\end{tabular}




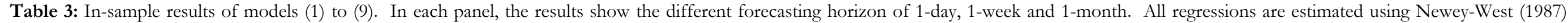
corrected standard errors. ${ }^{* *},{ }^{* *}$ and $*$ indicate significance at the $1 \%, 5 \%$ and $10 \%$ levels respectively.

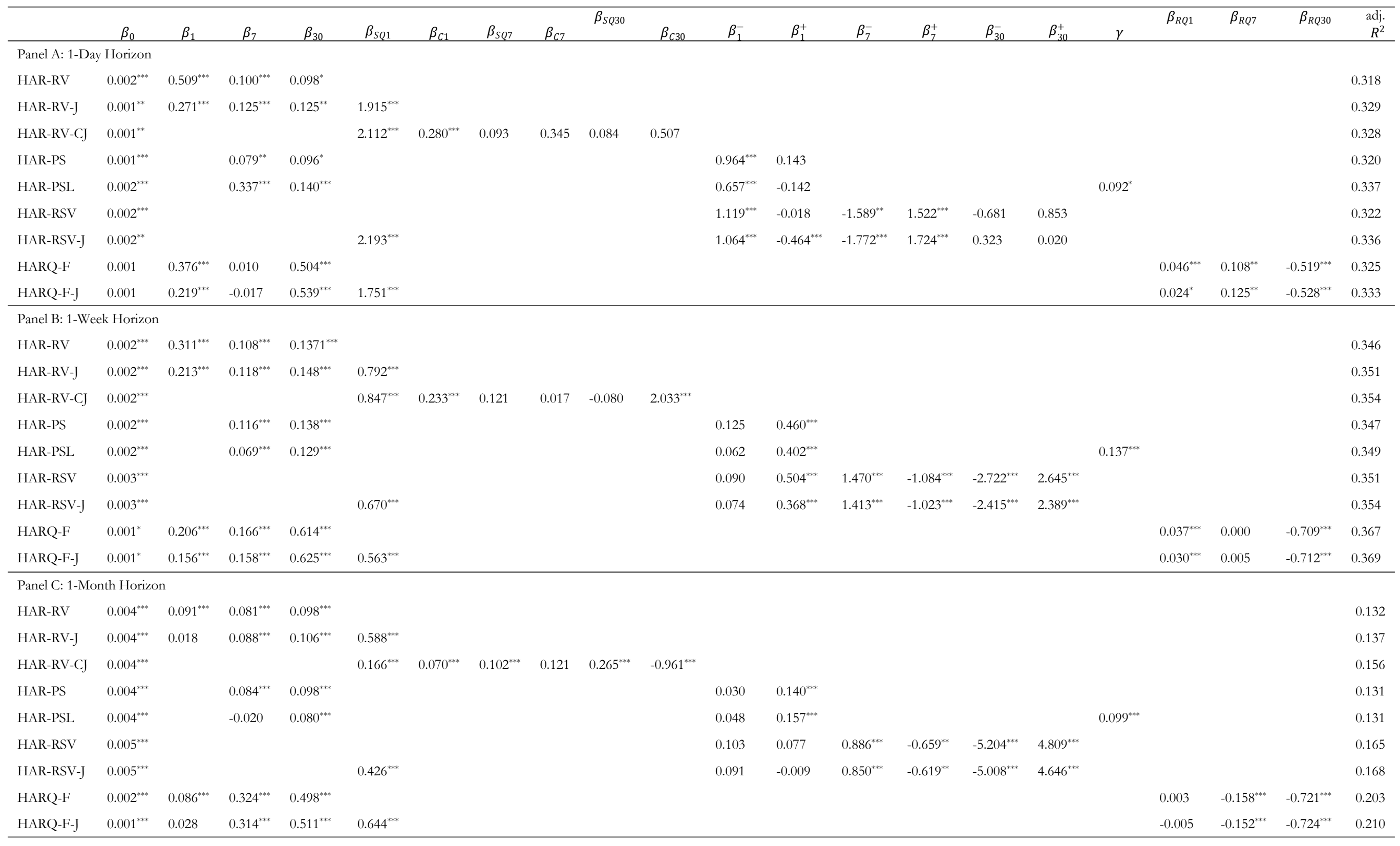




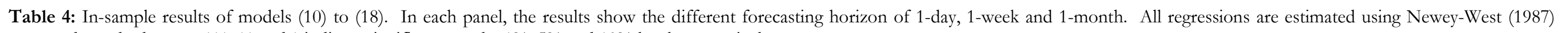
corrected standard errors. $* * *, * *$ and $*$ indicate significance at the $1 \%, 5 \%$ and $10 \%$ levels respectively.

\begin{tabular}{|c|c|c|c|c|c|c|c|c|c|c|c|c|c|c|c|c|c|c|c|c|c|c|}
\hline & $\beta_{0}$ & $\beta_{1}$ & $\beta_{7}$ & $\beta_{30}$ & $\beta_{C 1}$ & $\beta_{C 7}$ & $\beta_{C 30}$ & $\Delta J 1$ & $\Delta J 7$ & $\Delta J 30$ & $\Delta J_{1}^{-}$ & $\Delta J_{1}^{+}$ & $\Delta J_{7}^{-}$ & $\Delta J_{7}^{+}$ & $\Delta J_{30}^{-}$ & $\Delta J_{30}^{+}$ & $\beta_{R J}$ & $\beta_{R J^{+}}$ & $\beta_{R J^{-}}$ & $\beta_{S Q 1}$ & $\beta_{R Q 1}$ & $\begin{array}{l}\text { adj. } \\
R^{2}\end{array}$ \\
\hline \multicolumn{23}{|c|}{ Panel A: 1-Day Horizon } \\
\hline HARQ & $0.002^{2+*+}$ & $0.387^{7+* x}$ & $0.154^{* * * *}$ & $0.106^{* *}$ & & & & & & & & & & & & & & & & & $0.044^{* *+x}$ & 0.322 \\
\hline HARQ-J & $0.001^{\text {wex }}$ & $0.234^{* * *}$ & $0.150^{* * *}$ & $0.126^{* *}$ & & & & & & & & & & & & & & & & $1.714^{* * *+}$ & $0.023^{*}$ & 0.329 \\
\hline HAR-RV-SJ & $0.002^{2+*+}$ & & $0.089^{* *}$ & $0.087^{*}$ & $0.601^{*+* x}$ & & & $-0.288^{* *}$ & & & & & & & & & & & & & & 0.311 \\
\hline HAR-RV-CSJ & $0.002^{* *+*}$ & & & & $0.585^{*+*}$ & -0.093 & 0.108 & 0.147 & $1.927^{\text {tow }}$ & 0.819 & & & & & & & & & & & & 0.314 \\
\hline HAR-RV-SJD & $0.002^{2+1+}$ & & $0.137^{* \ldots+*}$ & 0.065 & $0.619^{*+* x}$ & & & & & & -0.168 & $-3.005^{*+* x}$ & & & & & & & & & & 0.323 \\
\hline HAR-RV-CSJD & $0.002^{2 * *+}$ & & & & $0.346^{+*+*}$ & 0.030 & 0.086 & & & & $-2.759^{m+*}$ & $1.007^{* * * *}$ & $3.593^{+*+*}$ & 0.197 & -0.278 & $2.218^{*}$ & & & & & & 0.328 \\
\hline HAR-J & $0.002^{* *+*}$ & & $0.104^{* *+*}$ & $0.089^{*}$ & $0.566^{* 3+1}$ & & & & & & & & & & & & & & & & & 0.310 \\
\hline HAR-RJ & $0.002^{* *+*}$ & & $0.191^{+\ldots+\ldots}$ & $0.096^{*}$ & 0.386 & & & & & & & & & & & & $-1.693^{\text {wa* }}$ & & & & & 0.341 \\
\hline HAR-ARJ & $0.002^{2 *+*}$ & & $0.188^{*+*}$ & $0.116^{*}$ & $0.245^{*+*}$ & & & & & & & & & & & & & -0.117 & $-2.675^{* * *}$ & & & 0.347 \\
\hline \multicolumn{23}{|c|}{ Panel B: 1-Week Horizon } \\
\hline HARQ & $0.002^{* *+*}$ & $0.223^{3+\cdots}$ & $0.147^{* w *}$ & $0.143^{*+*}$ & & & & & & & & & & & & & & & & & $0.032^{* *+}$ & 0.351 \\
\hline HARQ-J & $0.002^{2+*+}$ & $0.172^{2 * *}$ & $0.145^{\text {sex }}$ & $0.150^{w * *+}$ & & & & & & & & & & & & & & & & $0.573^{* * * *}$ & $0.025^{\text {tow }}$ & 0.353 \\
\hline HAR-RV-SJ & $0.002^{* *+*}$ & & $0.120^{+* *}$ & $0.133^{\ldots+\ldots}$ & $0.321^{\prime \ldots+*}$ & & & $0.223^{* *}$ & & & & & & & & & & & & & & 0.343 \\
\hline HAR-RV-CSJ & $0.003^{\text {tow }}$ & & & & $0.334^{* * *+}$ & $0.159^{* *+*}$ & -0.023 & $0.562^{w * *}$ & $-0.755^{5 *}$ & $2.449^{\text {tow }}$ & & & & & & & & & & & & 0.347 \\
\hline HAR-RV-SJD & $0.003^{\text {tex }}$ & & $0.137^{* * *+}$ & $0.125^{w *+}$ & $0.328^{*+*}$ & & & & & & $0.267^{\text {tow }}$ & $-0.763^{*+*}$ & & & & & & & & & & 0.347 \\
\hline HAR-RV-CSJD & $0.003^{*+*}$ & & & & $0.210^{*+1+}$ & $0.248^{* *+1}$ & -0.069 & & & & $-0.828^{m+n}$ & $0.943^{* * *}$ & -0.333 & $-1.919^{* * * *}$ & $2.440^{+2+2}$ & $3.445^{* *+1}$ & & & & & & 0.354 \\
\hline HAR-J & $0.002^{* *+*}$ & & $0.108^{* * *}$ & $0.132^{w+*}$ & $0.348^{*+*}$ & & & & & & & & & & & & & & & & & 0.342 \\
\hline HAR-RJ & $0.003^{\text {twa }}$ & & $0.134^{* * * *}$ & $0.134^{* * *+}$ & $0.294^{* * * *}$ & & & & & & & & & & & & $-0.505^{\text {tow }}$ & & & & & 0.348 \\
\hline HAR-ARJ & $0.002^{* * *+}$ & & $0.133^{* * *}$ & $0.146^{w+*}$ & $0.207^{+2+4}$ & & & & & & & & & & & & & $0.477^{*}$ & $-1.117^{* 0 * x}$ & & & 0.353 \\
\hline \multicolumn{23}{|c|}{ Panel C: 1-Month Horizon } \\
\hline HARQ & $0.004^{* *+*}$ & $0.105^{*+*}$ & $0.074^{* *+}$ & $0.097^{* *+*}$ & & & & & & & & & & & & & & & & & -0.005 & 0.132 \\
\hline HARQ-J & $0.004^{*+*}$ & $0.041^{*}$ & $0.073^{*+*}$ & $0.105^{* * *+}$ & & & & & & & & & & & & & & & & $0.712^{* * * *}$ & $-0.014^{* *}$ & 0.139 \\
\hline HAR-RV-SJ & $0.004^{\text {twa }}$ & & $0.087^{* * *}$ & $0.097^{* *+*}$ & $0.090^{*+*}$ & & & 0.080 & & & & & & & & & & & & & & 0.129 \\
\hline HAR-RV-CSJ & $0.005^{\text {w** }}$ & & & & $0.100^{+2+*}$ & $0.120^{*+*}$ & $-0.231^{*}$ & -0.005 & $-0.707^{* *}$ & $5.098^{+2+1}$ & & & & & & & & & & & & 0.163 \\
\hline HAR-RV-SJD & $0.004^{* *+4}$ & & $0.098^{+* *+}$ & $0.092^{* * *+}$ & $0.094^{*+*}$ & & & & & & 0.108 & $-0.556^{* * *}$ & & & & & & & & & & 0.133 \\
\hline HAR-RV-CSJD & $0.005^{*+*}$ & & & & $0.042^{*}$ & $0.129^{+* *+}$ & $-0.225^{+* *}$ & & & & $-0.603^{n+*}$ & $0.241^{*}$ & $-0.758^{* *}$ & -0.432 & $4.748^{+* *+}$ & $5.317^{\text {tw* }}$ & & & & & & 0.167 \\
\hline HAR-J & $0.004^{\text {twa }}$ & & $0.083^{* * *}$ & $0.096^{* *+}$ & $0.100^{*+*}$ & & & & & & & & & & & & & & & & & 0.129 \\
\hline HAR-RJ & $0.004^{\text {wat }}$ & & $0.083^{* * *}$ & $0.096^{* *+}$ & $0.099^{+*+*}$ & & & & & & & & & & & & -0.005 & & & & & 0.129 \\
\hline HAR-ARJ & $0.004^{* *+*}$ & & $0.081^{* \ldots+}$ & $0.107^{*+n+w}$ & 0.021 & & & & & & & & & & & & & $0.872^{+*+*}$ & $-0.551^{*+* x}$ & & & 0.138 \\
\hline
\end{tabular}




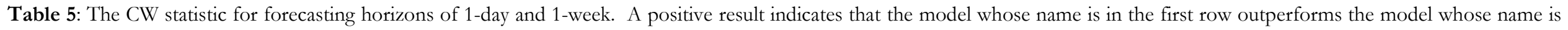
provided in the first column. The statistic is computed using Newey and West (1987). ***, **, * indicate significance at the $1 \%, 5 \%$ and $10 \%$ respectively.

\begin{tabular}{|c|c|c|c|c|c|c|c|c|c|c|c|c|c|c|c|c|c|}
\hline & $\begin{array}{l}\text { HAR- } \\
\text { RV-J }\end{array}$ & $\begin{array}{l}\text { HAR- } \\
\text { RV-CJ }\end{array}$ & $\begin{array}{l}\text { HAR- } \\
\text { PS }\end{array}$ & $\begin{array}{l}\text { HAR- } \\
\text { PSL }\end{array}$ & $\begin{array}{l}\text { HAR- } \\
\text { RSV }\end{array}$ & $\begin{array}{l}\text { HAR- } \\
\text { RSV-J }\end{array}$ & HARQ & $\begin{array}{l}\text { HARQ- } \\
\mathrm{J}\end{array}$ & HARQ-F & $\begin{array}{l}\text { HARQ- } \\
\text { F-J }\end{array}$ & $\begin{array}{l}\text { HAR- } \\
\text { RV-SJ }\end{array}$ & $\begin{array}{l}\text { HAR- } \\
\text { RV-CSJ }\end{array}$ & $\begin{array}{l}\text { HAR- } \\
\text { RV-SJD } \\
\end{array}$ & $\begin{array}{l}\text { HAR- } \\
\text { RV-CSJD }\end{array}$ & HAR-J & $\begin{array}{l}\text { HAR- } \\
\text { RJ }\end{array}$ & $\begin{array}{l}\text { HAR- } \\
\text { ARJ }\end{array}$ \\
\hline \multicolumn{18}{|c|}{ Panel A: 1-Day Horizon } \\
\hline HAR-RV & -0.240 & -0.017 & -0.897 & -1.328 & -1.057 & -0.721 & $2.086^{* *}$ & $1.610^{*}$ & $3.634^{* * * *}$ & $4.522^{* * *}$ & -0.707 & -0.893 & -0.691 & -0.825 & 0.690 & -1.613 & -1.154 \\
\hline HAR-RV-J & & 0.884 & -0.262 & -0.936 & -0.059 & -0.864 & $1.867^{* *}$ & $2.444^{* * * *}$ & $2.464^{* * *}$ & $4.432^{* * *}$ & $1.461^{*}$ & $1.477^{*}$ & $1.364^{*}$ & -0.722 & $1.432^{*}$ & -1.250 & -2.120 \\
\hline HAR-RV-CJ & & & -0.070 & -0.750 & 0.231 & -0.781 & $2.105^{* *}$ & $2.618^{* * * *}$ & $2.669^{* * *}$ & $4.600^{* * *}$ & $1.728^{* *}$ & $1.919^{* *}$ & $1.693^{* *}$ & -0.678 & $1.724^{* *}$ & -0.386 & -1.531 \\
\hline HAR-PS & & & & -1.970 & 0.649 & -0.646 & $1.502^{*}$ & $2.198^{* *}$ & $1.904^{* *}$ & $2.884^{* * *}$ & 1.106 & 0.911 & 0.988 & -0.904 & 1.057 & 0.713 & 0.866 \\
\hline HAR-PSL & & & & & $3.202^{* * * *}$ & $1.304^{*}$ & $2.246^{* *}$ & $3.227^{* * * *}$ & $2.558^{* * * *}$ & $3.688^{* * *}$ & $3.025^{* * *}$ & $2.464^{* * * *}$ & $2.816^{* * *}$ & -0.442 & $2.143^{* *}$ & $2.427^{* * * *}$ & $2.843^{* * * *}$ \\
\hline HAR-RSV & & & & & & -0.477 & $2.756^{* * *}$ & $4.717^{* * * *}$ & $3.233^{* * *}$ & $5.718^{* * *}$ & $4.839^{* * * *}$ & 0.859 & $4.144^{* * * *}$ & -0.804 & $2.524^{* * *}$ & $3.451^{* * *}$ & $3.731^{* * * *}$ \\
\hline HAR-RSV-J & & & & & & & $1.547^{*}$ & $1.749^{* *}$ & $1.660^{* *}$ & $1.904^{* *}$ & $1.607^{*}$ & 1.035 & $1.551^{*}$ & -0.805 & $1.416^{*}$ & $1.428^{*}$ & $1.407^{*}$ \\
\hline HARQ & & & & & & & & -0.185 & $5.054^{* * *}$ & $2.120^{* *}$ & -0.335 & -0.389 & -0.389 & -0.809 & -0.077 & -1.090 & -0.805 \\
\hline HARQ-J & & & & & & & & & $1.888^{* *}$ & $3.689^{* * *}$ & 0.477 & 0.678 & 0.431 & -0.801 & 1.067 & -1.140 & -1.278 \\
\hline HARQ-F & & & & & & & & & & -0.597 & -0.739 & -0.719 & -0.689 & -0.855 & -0.992 & -1.397 & -1.257 \\
\hline HARQ-F-J & & & & & & & & & & & 0.901 & $1.545^{*}$ & 1.002 & -0.673 & $1.687^{* *}$ & -0.268 & -0.889 \\
\hline HAR-RV-SJ & & & & & & & & & & & & 0.475 & 0.162 & -0.933 & 0.995 & -0.613 & -0.227 \\
\hline HAR-RV-CSJ & & & & & & & & & & & & & $3.767^{* * * *}$ & -0.785 & $4.237^{* * *}$ & $3.022^{* * *}$ & $2.542^{* * * *}$ \\
\hline HAR-RV-SJD & & & & & & & & & & & & & & -0.710 & $1.927^{* *}$ & 1.254 & 1.251 \\
\hline HAR-RV-CSJD & & & & & & & & & & & & & & & 1.220 & 1.232 & 1.275 \\
\hline HAR-J & & & & & & & & & & & & & & & & -1.439 & -0.936 \\
\hline HAR-RJ & & & & & & & & & & & & & & & & & 0.007 \\
\hline \multicolumn{18}{|c|}{ Panel B: 1-Week Horizon } \\
\hline HAR-RV & $1.408^{*}$ & $1.820^{* *}$ & 0.995 & 0.483 & 1.121 & $1.624^{*}$ & 1.149 & $2.794^{* * * *}$ & $17.811^{* * *}$ & $20.172^{* * *}$ & 0.856 & 0.230 & 0.619 & -0.438 & -0.229 & -2.907 & -0.118 \\
\hline HAR-RV-J & & 0.836 & 0.567 & 0.281 & 0.930 & $1.322^{*}$ & 0.649 & $1.292^{*}$ & $12.586^{* * *}$ & $17.141^{* * *}$ & 0.642 & 0.388 & 0.498 & -0.491 & 0.073 & -2.847 & -3.841 \\
\hline HAR-RV-CJ & & & $1.289^{*}$ & 1.021 & $1.745^{* *}$ & $2.157^{* *}$ & $1.525^{*}$ & $2.448^{* * * *}$ & $13.171^{* * *}$ & $16.793^{* * * *}$ & 1.192 & 1.058 & 1.034 & -0.111 & 1.187 & -0.015 & 0.379 \\
\hline HAR-PS & & & & -1.391 & 0.533 & 1.226 & 0.333 & $1.515^{*}$ & $21.860^{* * *}$ & $20.032^{2 * * *}$ & 0.319 & -0.585 & -0.302 & -0.133 & -0.919 & -1.828 & -0.253 \\
\hline HAR-PSL & & & & & $1.690^{* *}$ & $2.136^{* *}$ & $2.222^{* *}$ & $2.931^{* * * *}$ & $21.330^{* * *}$ & $20.305^{* * *}$ & $2.674^{* * *}$ & 0.640 & $1.967^{* *}$ & 0.092 & $1.456^{*}$ & -0.262 & 0.905 \\
\hline HAR-RSV & & & & & & $2.028^{* *}$ & $9.100^{* * * *}$ & $9.114^{* * * *}$ & $21.796^{* * *}$ & $21.027^{* * * *}$ & $7.796^{* * *}$ & -3.219 & $7.205^{* * *}$ & -0.826 & $8.747^{* * *}$ & $6.474^{* * *}$ & $6.369^{* * * *}$ \\
\hline HAR-RSV-J & & & & & & & $4.238^{* * * *}$ & $6.606^{* * * *}$ & $15.534^{* * *}$ & $19.195^{* * *}$ & $3.105^{* * *}$ & -0.889 & $2.860^{* * * *}$ & -1.258 & $5.474^{* * *}$ & $6.124^{* * * *}$ & $7.065^{* * * *}$ \\
\hline HARQ & & & & & & & & $2.057^{* *}$ & $20.833^{* * *}$ & $18.788^{* * * *}$ & $1.527^{*}$ & -0.039 & 0.881 & 0.001 & 0.469 & -1.066 & 0.511 \\
\hline HARQ-J & & & & & & & & & $18.066^{* * *}$ & $20.090^{* * * *}$ & 0.619 & -0.027 & 0.353 & -0.340 & -0.412 & -2.553 & -0.921 \\
\hline HARQ-F & & & & & & & & & & -0.539 & -11.785 & -3.904 & -11.414 & -1.961 & -12.026 & -10.518 & -9.381 \\
\hline HARQ-F-J & & & & & & & & & & & -5.069 & -1.343 & -4.981 & -1.109 & -9.132 & -8.368 & -8.198 \\
\hline HAR-RV-SJ & & & & & & & & & & & & -0.706 & -1.055 & 0.418 & -0.520 & -1.665 & 0.724 \\
\hline HAR-RV-CSJ & & & & & & & & & & & & & $10.589^{* * *}$ & 0.186 & $10.039^{* * * *}$ & $8.256^{* * *}$ & $8.259^{* * * *}$ \\
\hline HAR-RV-SJD & & & & & & & & & & & & & & 0.894 & $1.360^{*}$ & 0.033 & $1.958^{* *}$ \\
\hline HAR-RV-CSJD & & & & & & & & & & & & & & & $2.050^{* *}$ & $2.106^{* *}$ & $2.428^{* * *}$ \\
\hline HAR-J & & & & & & & & & & & & & & & & -1.940 & 0.480 \\
\hline HAR-RJ & & & & & & & & & & & & & & & & & $2.313^{* *}$ \\
\hline
\end{tabular}




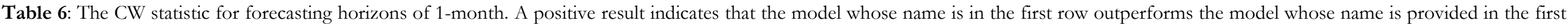
column. The statistic is computed using Newey and West (1987) HAC. ***, **, * indicate significance at the 1\%, 5\% and 10\% respectively.

\begin{tabular}{|c|c|c|c|c|c|c|c|c|c|c|c|c|c|c|c|c|c|}
\hline & $\begin{array}{l}\text { HAR- } \\
\text { RV-J } \\
\end{array}$ & $\begin{array}{l}\text { HAR- } \\
\text { RV-CJ }\end{array}$ & $\begin{array}{l}\text { HAR- } \\
\text { PS } \\
\end{array}$ & $\begin{array}{l}\text { HAR- } \\
\text { PSL }\end{array}$ & $\begin{array}{l}\text { HAR- } \\
\text { RSV }\end{array}$ & $\begin{array}{l}\text { HAR- } \\
\text { RSV-J }\end{array}$ & HARQ & $\begin{array}{l}\text { HARQ- } \\
\mathrm{J}\end{array}$ & HARQ-F & $\begin{array}{l}\text { HARQ- } \\
\text { F-J } \\
\end{array}$ & $\begin{array}{l}\text { HAR- } \\
\text { RV-SJ }\end{array}$ & $\begin{array}{l}\text { HAR- } \\
\text { RV-CSJ }\end{array}$ & $\begin{array}{l}\text { HAR- } \\
\text { RV-SJD } \\
\end{array}$ & $\begin{array}{l}\text { HAR- } \\
\text { RV-CSJD }\end{array}$ & HAR-J & $\begin{array}{l}\text { HAR- } \\
\text { RJ } \\
\end{array}$ & $\begin{array}{l}\text { HAR- } \\
\text { ARJ }\end{array}$ \\
\hline HAR-RV & $4.196^{* * *}$ & $13.799^{* * * *}$ & $1.284^{*}$ & 0.935 & -8.216 & -7.861 & $2.792^{* * *}$ & $4.237^{k * k *}$ & $22.916^{* * * *}$ & $21.909^{* * *}$ & 0.538 & -8.014 & -0.579 & -5.546 & -2.339 & -1.744 & $6.417^{* * * *}$ \\
\hline HAR-RV-J & & $12.697^{* * * *}$ & -1.513 & -1.477 & -8.184 & -8.517 & -2.186 & $2.518^{* 2 *+k}$ & $22.792^{* * *}$ & $22.238^{* * *}$ & -1.239 & -7.863 & -1.767 & -5.719 & -2.912 & -3.006 & $7.160^{* * *}$ \\
\hline HAR-RV-CJ & & & -10.526 & -10.338 & -11.407 & -11.570 & -10.816 & -6.183 & $20.295^{* * *}$ & $19.509^{* * *}$ & -9.508 & -11.057 & -9.817 & -7.970 & -11.429 & -11.474 & -9.239 \\
\hline HAR-PS & & & & -0.098 & -8.545 & -8.006 & 1.171 & $4.130^{* * * *}$ & $22.628^{* * * *}$ & $21.814^{* * *}$ & -1.002 & -8.410 & -2.378 & -5.881 & -2.216 & -2.127 & $5.553^{* * *}$ \\
\hline HAR-PSL & & & & & -8.119 & -7.562 & $2.407^{* * *}$ & $4.706^{* * * *}$ & $22.958^{* * *}$ & $22.135^{* * *}$ & $1.483^{*}$ & -8.008 & 0.021 & -5.701 & 0.605 & 0.319 & $5.914^{* * *}$ \\
\hline HAR-RSV & & & & & & $6.302^{* * *}$ & $13.986^{* * *}$ & $14.317^{* * * *}$ & $20.250^{* * *}$ & $20.114^{* * *}$ & $13.961^{* 2 * k}$ & -6.938 & $13.832^{* * *}$ & 0.378 & $13.843^{* * * *}$ & $13.844^{* * *}$ & $14.449^{*+* *}$ \\
\hline HAR-RSV-J & & & & & & & $13.705^{* * *}$ & $14.089^{* * * *}$ & $20.347^{* * * *}$ & $20.190^{* * *}$ & $13.387^{* * * *}$ & -4.548 & $13.220^{* * * *}$ & -1.112 & $13.475^{* * *}$ & $13.495^{5 * *}$ & $14.285^{* * *}$ \\
\hline HARQ & & & & & & & & $3.719^{* * *}$ & $22.922^{* * *}$ & $21.891^{* * *}$ & -0.209 & -7.968 & -1.003 & -5.569 & -2.722 & -2.998 & $5.568^{* * *}$ \\
\hline HARQ-J & & & & & & & & & $21.607^{* * *}$ & $22.906^{* * *}$ & -0.972 & -6.591 & -1.220 & -6.089 & -1.837 & -1.902 & -0.074 \\
\hline HARQ-F & & & & & & & & & & $1.805^{* *}$ & -20.325 & -13.679 & -20.139 & -10.535 & -22.361 & -22.369 & -21.550 \\
\hline HARQ-F-J & & & & & & & & & & & -11.614 & -10.318 & -11.511 & -10.286 & -14.896 & -15.064 & -17.344 \\
\hline HAR-RV-SJ & & & & & & & & & & & & -8.386 & -2.315 & -6.040 & -0.740 & -0.777 & $5.695^{* * *}$ \\
\hline HAR-RV-CSJ & & & & & & & & & & & & & $13.769^{* * * *}$ & $1.580^{*}$ & $13.781^{* * * *}$ & $13.787^{* * *}$ & $14.367^{* * * *}$ \\
\hline HAR-RV-SJD & & & & & & & & & & & & & & -5.758 & $1.478^{*}$ & $1.474^{*}$ & $6.714^{* * *}$ \\
\hline HAR-RV-CSJD & & & & & & & & & & & & & & & $7.206^{* * *}$ & $7.243^{* * * *}$ & $8.163^{* * *}$ \\
\hline HAR-J & & & & & & & & & & & & & & & & 0.082 & $6.284^{* * *}$ \\
\hline HAR-RJ & & & & & & & & & & & & & & & & & $6.499^{* * *}$ \\
\hline
\end{tabular}


Table 7: The breakpoint dates and standard deviation identified by the ICSS algorithm.

\begin{tabular}{|c|c|c|}
\hline Total Breaks points & Time period & Standard deviation \\
\hline 1 & January 01, 2012 - March 19, 2012 & 0.211 \\
\hline 2 & March 20, 2012 - August 14, 2012 & 0.075 \\
\hline 3 & August 15, 2012 - August 20, 2012 & 0.466 \\
\hline 4 & August 21, 2012 - September 01, 2012 & 0.207 \\
\hline 5 & September 02, 2012 - October 29, 2012 & 0.070 \\
\hline 6 & October 30, 2012 - January 16, 2013 & 0.035 \\
\hline 7 & January 17, 2013 - March 18, 2013 & 0.098 \\
\hline 8 & March 19, 2013 - April 09, 2013 & 0.193 \\
\hline 9 & April 10, 2013 - April 12, 2013 & 1.327 \\
\hline 10 & April 13, 2013 - May 04, 2013 & 0.398 \\
\hline 11 & May 05, 2013 - June 30, 2013 & 0.108 \\
\hline 12 & July 01, 2013 - July 18, 2013 & 0.216 \\
\hline 13 & July 19, 2013 - October 01, 2013 & 0.065 \\
\hline 14 & October 02, 2013 - November 17, 2013 & 0.169 \\
\hline 15 & November 18, 2013 - December 20, 2013 & 0.421 \\
\hline 16 & December 21, 2013 - March 26, 2014 & 0.142 \\
\hline 17 & March 27, 2014 - April 19, 2014 & 0.245 \\
\hline 18 & April 20, 2014 - January 02, 2015 & 0.091 \\
\hline 19 & January 03, 2015 - January 15, 2015 & 0.312 \\
\hline 20 & January 16, 2015 - February 15, 2015 & 0.173 \\
\hline 21 & February 16, 2015 - August 25, 2015 & 0.080 \\
\hline 22 & August 26, 2015 - October 29, 2015 & 0.048 \\
\hline 23 & October 30, 2015 - January 22, 2016 & 0.132 \\
\hline 24 & January 23, 2016 - February 23, 2016 & 0.071 \\
\hline 25 & February 24, 2016 - April 18, 2016 & 0.036 \\
\hline 26 & April 19, 2016 - June 10, 2016 & 0.062 \\
\hline 27 & June 11, 2016 - August 03, 2016 & 0.124 \\
\hline 28 & August 04, 2016 - October 21, 2016 & 0.035 \\
\hline 29 & October 22, 2016 - November 04, 2016 & 0.094 \\
\hline 30 & November 05, 2016 - January 03, 2017 & 0.051 \\
\hline 31 & January 04, 2017 - May 22, 2017 & 0.113 \\
\hline 32 & May 23, 2017 - December 05, 2017 & 0.151 \\
\hline 33 & December 06, 2017 - February 14, 2018 & 0.226 \\
\hline 34 & February 15, 2018 - April 28, 2018 & 0.150 \\
\hline 35 & April 29, 2018 - September 30, 2018 & 0.092 \\
\hline
\end{tabular}




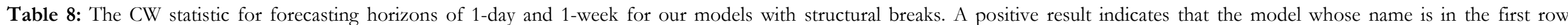

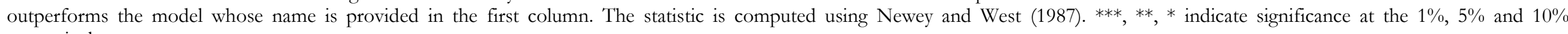
respectively.

\begin{tabular}{|c|c|c|c|c|c|c|c|c|c|c|c|c|c|c|c|c|c|}
\hline & $\begin{array}{l}\text { HAR- } \\
\text { RV-J }\end{array}$ & $\begin{array}{l}\text { HAR- } \\
\text { RV-CJ }\end{array}$ & $\begin{array}{l}\text { HAR- } \\
\text { PS }\end{array}$ & $\begin{array}{l}\text { HAR- } \\
\text { PSL }\end{array}$ & $\begin{array}{l}\text { HAR- } \\
\text { RSV }\end{array}$ & $\begin{array}{l}\text { HAR- } \\
\text { RSV-J }\end{array}$ & HARQ & $\begin{array}{l}\text { HARQ- } \\
\mathrm{J}\end{array}$ & HARQ-F & $\begin{array}{l}\text { HARQ- } \\
\text { F-J }\end{array}$ & $\begin{array}{l}\text { HAR- } \\
\text { RV-SJ }\end{array}$ & $\begin{array}{l}\text { HAR- } \\
\text { RV-CSJ }\end{array}$ & $\begin{array}{l}\text { HAR- } \\
\text { RV-SJD }\end{array}$ & $\begin{array}{l}\text { HAR- } \\
\text { RV-CSJD }\end{array}$ & HAR-J & $\begin{array}{l}\text { HAR- } \\
\text { RJ }\end{array}$ & $\begin{array}{l}\text { HAR- } \\
\text { ARJ }\end{array}$ \\
\hline \multicolumn{18}{|c|}{ Panel A: 1-Day Horizon } \\
\hline HAR-RV & -0.376 & -0.157 & -0.240 & $4.448^{* * * *}$ & 0.209 & -0.250 & $7.650^{* * * *}$ & $7.319^{* * * *}$ & $7.965^{* * *}$ & $7.571^{* * * *}$ & 1.131 & $1.539^{*}$ & 0.677 & 0.111 & $2.382^{* * *}$ & -1.537 & -0.223 \\
\hline HAR-RV-J & & 0.032 & 0.792 & $3.816^{* * *}$ & $1.624^{*}$ & -0.518 & $7.573^{* * * *}$ & $7.226^{* * * *}$ & $7.815^{* * *}$ & $7.599^{* * * *}$ & $3.014^{* * * *}$ & $2.594^{* * * *}$ & 1.086 & -0.131 & $1.551^{*}$ & -0.783 & 0.574 \\
\hline HAR-RV-CJ & & & $1.405^{*}$ & $3.876^{* * * *}$ & $2.359^{* * * *}$ & -0.327 & $7.354^{* * * *}$ & $7.095^{* * *}$ & $7.524^{* * *}$ & $7.397^{* * * *}$ & $3.336^{* * * *}$ & $2.939^{* * * *}$ & $1.285^{*}$ & -0.084 & $1.798^{* *}$ & 0.233 & 1.177 \\
\hline HAR-PS & & & & $3.686^{* * *}$ & 1.140 & -0.643 & $7.714^{* * * *}$ & $8.225^{* * *}$ & $7.647^{* * * *}$ & $8.742^{* * * *}$ & $1.658^{* *}$ & $1.371^{*}$ & 0.852 & -0.431 & 1.167 & 0.404 & 1.044 \\
\hline HAR-PSL & & & & & $1.874^{* *}$ & $2.579^{* * *}$ & $2.262^{* *}$ & $3.035^{* * *}$ & $2.222^{* *}$ & $3.031^{* * * *}$ & $1.815^{* *}$ & $1.767^{* *}$ & $1.569^{*}$ & -0.290 & $1.609^{*}$ & $1.695^{* *}$ & $1.633^{*}$ \\
\hline HAR-RSV & & & & & & -0.860 & $8.860^{* * * *}$ & $8.616^{* * *}$ & $9.193^{* * *}$ & $9.238^{* * * *}$ & $4.170^{* * * *}$ & $1.505^{*}$ & $1.792^{* *}$ & -0.366 & $2.274^{* *}$ & $2.355^{* * *}$ & $2.901^{* * *}$ \\
\hline HAR-RSV-J & & & & & & & $4.043^{* * *}$ & $5.502^{* * *}$ & $3.706^{* * *}$ & $5.268^{* * * *}$ & $1.623^{*}$ & 1.216 & $1.317^{*}$ & -0.350 & $1.448^{*}$ & $1.423^{*}$ & $1.469^{*}$ \\
\hline HARQ & & & & & & & & -0.319 & 0.630 & 0.050 & -0.003 & 0.252 & 0.432 & -0.879 & 0.210 & -0.412 & -0.309 \\
\hline HARQ-J & & & & & & & & & $2.771^{* * * *}$ & 0.722 & $2.614^{* * * *}$ & $2.400^{* * * *}$ & $2.007^{* *}$ & -0.309 & $2.146^{* *}$ & $2.213^{* *}$ & $2.177^{* *}$ \\
\hline HARQ-F & & & & & & & & & & -0.108 & -0.819 & -0.588 & -0.030 & -0.907 & -0.584 & -1.595 & -1.424 \\
\hline HARQ-F-J & & & & & & & & & & & $2.724^{* * * *}$ & $2.481^{* * * *}$ & $2.009^{* *}$ & -0.259 & $2.076^{* *}$ & $2.120^{* *}$ & $2.090^{* *}$ \\
\hline HAR-RV-SJ & & & & & & & & & & & & 0.627 & 0.251 & -0.458 & 0.737 & -2.138 & -0.499 \\
\hline HAR-RV-CSJ & & & & & & & & & & & & & $1.780^{* *}$ & -0.350 & $2.815^{* * *}$ & $1.320^{*}$ & $2.403^{* * *}$ \\
\hline HAR-RV-SJD & & & & & & & & & & & & & & $1.445^{*}$ & $2.586^{* * *}$ & $1.673^{* *}$ & $1.998^{* *}$ \\
\hline HAR-RV-CSJD & & & & & & & & & & & & & & & 1.146 & 1.147 & 1.152 \\
\hline HAR-J & & & & & & & & & & & & & & & & -2.273 & -1.054 \\
\hline HAR-RJ & & & & & & & & & & & & & & & & & $2.446^{* * * *}$ \\
\hline \multicolumn{18}{|c|}{ Panel B: 1-Week Horizon } \\
\hline HAR-RV & 0.263 & 1.060 & -2.074 & $1.872^{* *}$ & 0.041 & -0.155 & $1.873^{* *}$ & $1.873^{* *}$ & $1.871^{* *}$ & $1.870^{* *}$ & -1.321 & -0.007 & -2.015 & 0.039 & -1.220 & -1.684 & -1.900 \\
\hline HAR-RV-J & & 1.136 & -1.080 & $1.851^{* *}$ & -0.056 & -0.278 & $1.853^{* *}$ & $1.852^{* *}$ & $1.850^{* *}$ & $1.849^{* *}$ & -0.729 & -0.109 & -2.021 & -0.060 & -0.694 & -1.226 & -1.979 \\
\hline HAR-RV-CJ & & & -2.145 & $1.751^{* *}$ & -1.711 & -1.709 & $1.753^{* *}$ & $1.753^{* *}$ & $1.750^{* *}$ & $1.749^{* *}$ & -1.917 & -1.717 & -1.802 & -1.689 & -1.863 & -2.053 & -1.806 \\
\hline HAR-PS & & & & $1.876^{* *}$ & 0.141 & -0.060 & $1.878^{* *}$ & $1.878^{* *}$ & $1.875^{* *}$ & $1.874^{* *}$ & -0.318 & 0.094 & -2.016 & 0.150 & -0.156 & -1.207 & -1.873 \\
\hline HAR-PSL & & & & & $1.839^{* *}$ & $1.832^{* *}$ & $4.577^{* * * *}$ & $4.378^{* * *}$ & $4.664^{* * * *}$ & $3.520^{* * * *}$ & $1.752^{* *}$ & $1.852^{* *}$ & $1.793^{* *}$ & $1.860^{* *}$ & $1.719^{* *}$ & $1.721^{* *}$ & $1.725^{* *}$ \\
\hline HAR-RSV & & & & & & -1.655 & $1.766^{* *}$ & $1.766^{* *}$ & $1.762^{* *}$ & $1.761^{* *}$ & $1.621^{*}$ & -2.238 & -1.844 & 0.596 & $1.636^{*}$ & $1.627^{*}$ & -1.377 \\
\hline HAR-RSV-J & & & & & & & $1.763^{* *}$ & $1.763^{* *}$ & $1.759^{* *}$ & $1.758^{* *}$ & $1.668^{* *}$ & $1.617^{*}$ & -1.823 & $1.684^{* *}$ & $1.677^{* *}$ & $1.675^{* *}$ & 0.601 \\
\hline HARQ & & & & & & & & -0.291 & $3.048^{* * * *}$ & $2.276^{* *}$ & $1.715^{* *}$ & $1.829^{* *}$ & $1.755^{* *}$ & $1.850^{* *}$ & $1.688^{* *}$ & $1.692^{* *}$ & $1.701^{* *}$ \\
\hline HARQ-J & & & & & & & & & $3.322^{* * *}$ & $2.311^{* *}$ & $1.720^{* *}$ & $1.828^{* *}$ & $1.762^{* *}$ & $1.840^{* *}$ & $1.690^{* *}$ & $1.689^{* *}$ & $1.699^{* *}$ \\
\hline HARQ-F & & & & & & & & & & -2.489 & $1.636^{*}$ & $1.665^{* *}$ & $1.691^{* *}$ & $1.707^{* *}$ & $1.620^{*}$ & $1.614^{*}$ & $1.626^{*}$ \\
\hline HARQ-F-J & & & & & & & & & & & $1.691^{* *}$ & $1.707^{* *}$ & $1.743^{* *}$ & $1.738^{* *}$ & $1.671^{* *}$ & $1.659^{* *}$ & $1.666^{* *}$ \\
\hline HAR-RV-SJ & & & & & & & & & & & & 0.161 & -2.010 & 0.213 & $1.509^{*}$ & -1.527 & -1.780 \\
\hline HAR-RV-CSJ & & & & & & & & & & & & & -1.869 & $1.335^{*}$ & $1.586^{*}$ & $1.574^{*}$ & -1.280 \\
\hline HAR-RV-SJD & & & & & & & & & & & & & & $1.385^{*}$ & $2.035^{* *}$ & $2.050^{* *}$ & $1.846^{* *}$ \\
\hline HAR-RV-CSJD & & & & & & & & & & & & & & & $1.626^{*}$ & $1.610^{*}$ & -1.253 \\
\hline HAR-J & & & & & & & & & & & & & & & & -1.783 & -1.798 \\
\hline HAR-RJ & & & & & & & & & & & & & & & & & -1.784 \\
\hline
\end{tabular}




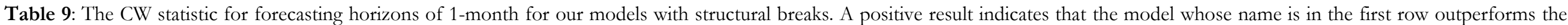
model whose name is provided in the first column. The statistic is computed using Newey and West (1987). ***, **, * indicate significance at the $1 \%, 5 \%$ and $10 \%$ respectively.

\begin{tabular}{|c|c|c|c|c|c|c|c|c|c|c|c|c|c|c|c|c|c|}
\hline & $\begin{array}{l}\text { HAR- } \\
\text { RV-J }\end{array}$ & $\begin{array}{l}\text { HAR- } \\
\text { RV-CJ }\end{array}$ & $\begin{array}{l}\text { HAR- } \\
\text { PS }\end{array}$ & $\begin{array}{l}\text { HAR- } \\
\text { PSL }\end{array}$ & $\begin{array}{l}\text { HAR- } \\
\text { RSV }\end{array}$ & $\begin{array}{l}\text { HAR- } \\
\text { RSV-J }\end{array}$ & HARQ & $\begin{array}{l}\text { HARQ- } \\
\mathrm{J}\end{array}$ & HARQ-F & $\begin{array}{l}\text { HARQ- } \\
\text { F-J }\end{array}$ & $\begin{array}{l}\text { HAR- } \\
\text { RV-SJ }\end{array}$ & $\begin{array}{l}\text { HAR- } \\
\text { RV-CSJ }\end{array}$ & $\begin{array}{l}\text { HAR- } \\
\text { RV-SJD }\end{array}$ & $\begin{array}{l}\text { HAR- } \\
\text { RV-CSJD }\end{array}$ & HAR-J & $\begin{array}{l}\text { HAR- } \\
\text { RJ }\end{array}$ & $\begin{array}{l}\text { HAR- } \\
\text { ARJ }\end{array}$ \\
\hline HAR-RV & $1.858^{* *}$ & $3.569^{* * * *}$ & 0.864 & $4.250^{* * *}$ & 1.083 & $2.024^{* *}$ & $4.252^{* * *}$ & $4.252^{* * *}$ & $4.232^{* * * *}$ & $4.231^{* * * *}$ & 0.589 & 0.856 & -4.809 & $1.450^{*}$ & -4.471 & 0.542 & -0.977 \\
\hline HAR-RV-J & & $2.848^{* * * *}$ & -5.284 & $3.976^{* * *}$ & 1.098 & $1.622^{*}$ & $3.978^{* * * *}$ & $3.977^{* * * *}$ & $3.959^{* * * *}$ & $3.958^{* * * *}$ & -5.027 & 0.972 & -5.036 & 1.247 & 0.011 & -4.913 & -4.164 \\
\hline HAR-RV-CJ & & & $2.415^{* * *}$ & $4.555^{* * * *}$ & -3.131 & -0.461 & $4.557^{* * * *}$ & $4.556^{* * *}$ & $4.573^{* * * *}$ & $4.571^{* * * *}$ & $2.418^{* * * *}$ & -3.124 & $1.452^{*}$ & -0.413 & $2.172^{* *}$ & $2.372^{* * *}$ & $1.885^{* *}$ \\
\hline HAR-PS & & & & $4.282^{* * *}$ & $1.436^{*}$ & $2.042^{* *}$ & $4.284^{* * *}$ & $4.283^{* * * *}$ & $4.261^{* * * *}$ & $4.260^{* * * *}$ & -4.011 & 1.237 & -4.763 & $1.470^{*}$ & 0.751 & -3.706 & -0.271 \\
\hline HAR-PSL & & & & & $6.103^{* * * *}$ & $6.110^{* * * *}$ & $3.826^{* * *}$ & $4.000^{* * * *}$ & $7.244^{* * *}$ & $6.978^{* * * *}$ & $5.769^{* * *}$ & $6.239^{* * * *}$ & $5.657^{* * *}$ & $6.469^{* * *}$ & $5.595^{* * *}$ & $5.678^{* * * *}$ & $5.465^{* * *}$ \\
\hline HAR-RSV & & & & & & $2.131^{* *}$ & $5.093^{* * *}$ & $5.092^{* * *}$ & $5.074^{* * *}$ & $5.073^{* * *}$ & $3.054^{* * *}$ & -5.327 & $2.063^{* *}$ & 0.831 & $2.938^{* * *}$ & $3.060^{* * * *}$ & $3.046^{* * * *}$ \\
\hline HAR-RSV-J & & & & & & & $5.006^{* * * *}$ & $5.006^{* * *}$ & $4.986^{* * *}$ & $4.986^{* * *}$ & $3.383^{* * * *}$ & $1.662^{* *}$ & $2.684^{* * *}$ & -5.738 & $3.410^{* * *}$ & $3.388^{* * *}$ & $3.274^{* * *}$ \\
\hline HARQ & & & & & & & & 0.614 & $6.830^{* * * *}$ & $6.545^{* * *}$ & $5.665^{* * *}$ & $6.157^{* * *}$ & $5.567^{* * *}$ & $6.384^{* * *}$ & $5.502^{* * *}$ & $5.578^{* * * *}$ & $5.368^{* * * *}$ \\
\hline HARQ-J & & & & & & & & & $6.740^{* * * *}$ & $6.312^{* * * *}$ & $5.676^{* * *}$ & $6.196^{* * * *}$ & $5.575^{* * *}$ & $6.410^{* * *}$ & $5.513^{* * *}$ & $5.581^{* * *}$ & $5.362^{* * * *}$ \\
\hline HARQ-F & & & & & & & & & & -1.644 & 0.242 & 0.345 & -0.146 & -0.638 & 0.714 & 0.285 & 0.359 \\
\hline HARQ-F-J & & & & & & & & & & & 0.018 & 0.149 & -0.399 & -0.760 & 0.446 & 0.030 & 0.071 \\
\hline HAR-RV-SJ & & & & & & & & & & & & $1.389^{*}$ & -4.502 & $1.609^{*}$ & 1.061 & -1.741 & 1.090 \\
\hline HAR-RV-CSJ & & & & & & & & & & & & & $2.288^{* *}$ & 1.237 & $3.201^{* * *}$ & $3.310^{* * * *}$ & $3.346^{* * * *}$ \\
\hline HAR-RV-SJD & & & & & & & & & & & & & & $2.715^{* * *}$ & $3.188^{* * * *}$ & $3.187^{* * * *}$ & $5.094^{* * * *}$ \\
\hline HAR-RV-CSJD & & & & & & & & & & & & & & & $4.052^{* * *}$ & $4.045^{* * *}$ & $4.072^{* * *}$ \\
\hline HAR-J & & & & & & & & & & & & & & & & 0.942 & 0.871 \\
\hline HAR-RJ & & & & & & & & & & & & & & & & & 1.246 \\
\hline
\end{tabular}


Table 10: The CW statistic for forecasting horizons of 1-day, 1-week, 1-month for our models with structural breaks and without structural breaks. Positive statistics indicate that HAR models with structural breaks (alternative models) outperform the corresponding HAR model without structural breaks (null models). ***, $* *$ and $*$ indicate significance at the $1 \%, 5 \%$ and $10 \%$ respectively.

\begin{tabular}{clll}
\hline & $\mathrm{h}=1$ & $\mathrm{~h}=7$ & $\mathrm{~h}=30$ \\
\hline HAR-RV & $1.794^{* *}$ & $2.497^{* * *}$ & 0.731 \\
HAR-RV-J(BPV) & $1.332^{*}$ & $2.448^{* * *}$ & $1.656^{* *}$ \\
HAR-RV-CJ(BPV) & 1.270 & $2.350^{* * *}$ & $4.248^{* * *}$ \\
HAR-PS & $1.654^{* *}$ & $2.480^{* * *}$ & 0.424 \\
HAR-PSL & $7.087^{* * *}$ & $16.058^{* * *}$ & $21.680^{* * *}$ \\
HAR-RSV & $2.573^{* * *}$ & $4.895^{* * *}$ & $3.373^{* * *}$ \\
HAR-RSV-J(BPV) & $1.709^{* *}$ & $4.352^{* * *}$ & $4.319^{* * *}$ \\
HARQ & $2.114^{* *}$ & -2.432 & $7.551^{* * *}$ \\
HARQ-J(BPV) & $1.353^{*}$ & $4.796^{* * *}$ & $15.937^{* * *}$ \\
HARQ-F & $7.548^{* * *}$ & $16.319^{* * *}$ & $21.556^{* * *}$ \\
HARQ-F-J(BPV) & $4.377^{* * *}$ & $17.191^{* * *}$ & $22.244^{* * *}$ \\
HAR-RV-SJ(BPV) & $1.975^{* *}$ & $2.511^{* * *}$ & 0.108 \\
HAR-RV-CSJ(BPV) & $3.398^{* * *}$ & $5.411^{* * *}$ & $2.717^{* * *}$ \\
HAR-RV-SJD(BPV) & $1.569^{*}$ & $2.365^{* * *}$ & -0.986 \\
HAR-RV-CSJD(BPV) & $1.920^{* *}$ & $4.691^{* * *}$ & $2.415^{* * *}$ \\
HAR-J(BPV) & $2.100^{* *}$ & $2.538^{* * *}$ & 0.339 \\
HAR-RJ & $2.040^{* *}$ & $2.656^{* * *}$ & 0.357 \\
HAR-ARJ & $1.529^{*}$ & $2.484^{* * *}$ & 0.704 \\
\hline
\end{tabular}


Table 11: The CW statistic for forecasting horizons of 1-day, 1-week and 1-month for MED models. A positive result indicates that the model whose name is in the first row outperforms the model whose name is provided in the first column. The statistic is computed using Newey and West (1987) HAC. ***, **, * indicate significance at the 1\%, $5 \%$ and $10 \%$ respectively.

\begin{tabular}{|c|c|c|c|c|c|c|c|c|}
\hline & $\begin{array}{l}\text { HAR- } \\
\text { RV-CJ }\end{array}$ & $\begin{array}{l}\text { HAR- } \\
\text { RSV-J }\end{array}$ & HARQ-J & $\begin{array}{l}\text { HARQ- } \\
\text { F-J }\end{array}$ & $\begin{array}{l}\text { HAR- } \\
\text { RV-SJ }\end{array}$ & $\begin{array}{l}\text { HAR- } \\
\text { RV-CSJ }\end{array}$ & $\begin{array}{l}\text { HAR- } \\
\text { RV-SJD }\end{array}$ & $\begin{array}{l}\text { HAR- } \\
\text { RV-CSJD }\end{array}$ \\
\hline \multicolumn{9}{|c|}{ Panel A: 1-Day Horizon } \\
\hline HAR-RV-J & -1.907 & -0.880 & 0.789 & $2.492^{* * *}$ & $1.533^{*}$ & $1.298^{*}$ & $1.396^{*}$ & -0.713 \\
\hline HAR-RV-CJ & & -0.661 & $1.498^{*}$ & $3.298^{* * *}$ & $2.296^{* *}$ & $1.815^{* *}$ & $2.162^{* *}$ & -0.540 \\
\hline HAR-RSV-J & & & $1.432^{*}$ & $1.508^{*}$ & 1.202 & 1.050 & 1.166 & -0.723 \\
\hline HARQ-J & & & & $2.888^{* * *}$ & $1.394^{*}$ & $1.308^{*}$ & $1.300^{*}$ & -0.731 \\
\hline HARQ-F-J & & & & & $1.544^{*}$ & $1.433^{*}$ & $1.487^{*}$ & -0.671 \\
\hline HAR-RV-SJ & & & & & & -0.362 & -0.136 & -0.809 \\
\hline HAR-RV-CSJ & & & & & & & $4.470^{* * *}$ & -0.251 \\
\hline HAR-RV-SJD & & & & & & & & -0.327 \\
\hline \multicolumn{9}{|c|}{ Panel B: 1-Week Horizon } \\
\hline HAR-RV-J & -1.299 & -0.353 & $2.286^{* *}$ & $17.977^{* * *}$ & 1.084 & 0.681 & 0.942 & -0.338 \\
\hline HAR-RV-CJ & & 0.422 & $3.593^{* * *}$ & $18.565^{* * *}$ & $1.546^{*}$ & 1.072 & $1.407^{*}$ & 0.051 \\
\hline HAR-RSV-J & & & $3.564^{* * *}$ & $9.154^{* * *}$ & $1.880^{* *}$ & 0.985 & $1.797^{* *}$ & -0.356 \\
\hline HARQ-J & & & & $18.449^{* * *}$ & 1.215 & 0.753 & 1.050 & -0.199 \\
\hline HARQ-F-J & & & & & -2.776 & -1.462 & -2.951 & -1.671 \\
\hline HAR-RV-SJ & & & & & & -1.705 & -0.098 & $1.573^{*}$ \\
\hline HAR-RV-CSJ & & & & & & & $10.337^{* * *}$ & $2.069^{* *}$ \\
\hline HAR-RV-SJD & & & & & & & & $1.803^{* *}$ \\
\hline \multicolumn{9}{|c|}{ Panel C: 1-Month Horizon } \\
\hline HAR-RV-J & $20.201^{* * *}$ & -8.259 & $2.057^{* *}$ & $19.325^{* * *}$ & 1.204 & -6.418 & 0.444 & -4.709 \\
\hline HAR-RV-CJ & & -12.635 & -1.813 & $17.497^{* * *}$ & -7.729 & -10.765 & -8.425 & -8.206 \\
\hline HAR-RSV-J & & & $12.645^{* * *}$ & $19.366^{* * *}$ & $13.938^{* * *}$ & $7.945^{* * *}$ & $13.801^{* * *}$ & $3.972^{* * *}$ \\
\hline HARQ-J & & & & $20.136^{* * *}$ & 0.442 & -0.961 & 0.362 & -6.624 \\
\hline HARQ-F-J & & & & & -3.547 & -3.588 & -3.660 & -12.811 \\
\hline HAR-RV-SJ & & & & & & -7.917 & -1.843 & -5.903 \\
\hline HAR-RV-CSJ & & & & & & & $13.866^{* * *}$ & $4.500^{* * *}$ \\
\hline HAR-RV-SJD & & & & & & & & -5.367 \\
\hline
\end{tabular}

